\title{
Index for Volume 97
}

AUTHOR AND SUBJECT INDEX. Pages indicating errata are in italic.

Abad, J. A., 1440

Abad, L. R., S149

Abawi, G., S86, S141

Abbas, H. K., S1

Abd-Elsalam, K., S44

Abdi, I., S180

Abel, C. A., S1

Abeln, E. C. A., 1112

Able, A. J., 907

Abney, S., S106

Abou Ghanem-Sabanadzovic, N., S1, S102, S103

Abril, M., S180

Abubucker, S., S156

Acacia koa

-Fusarium oxysporum, Hawaii, S168

-Fusarium wilt and dieback, Hawaii, S51

Accinelli, C., S1

Achbani, E. H., 338

Achor, D., 145

Acidovorax avenae, on watermelon:

—seed infection, S132

—seed priming, S35

Acosta-Leal, R., 325 S2, S170

Acremonium spp.

-A. strictum, parasitism of Helminthosporium solani, 1331

-A. zeae, on maize, endophyte, fermentation extracts, S94

Adams, B., S143

Adams, M. L., S2

Adaskaveg, J. E., S2, S36, S74, S111, S126

Adesemoye, A. O., S180

Adhikari, T. B., 835, 1608, S3, S15, S85, S160

Adkins, S., 145, S2, S59, S97, S99, S131, S182

Aerobiology, vehicle, sampling, S184

African cassava mosaic virus

-on cassava, nutrition, S86

- East African cassava mosaic Cameroon virus comparison, Nigeria, S3

Agaricus spp., green mold, Trichoderma spp. cause, 532

Agarkova, I., 803

Ageratum yellow vein China virus, DNA $\beta$ molecule association, 405

Agindotan, B., 119, S2, S153

Agrobacterium tumefaciens

- salicylic acid modulation, $\mathrm{S} 4$

—on walnut, genetic diversity, California, S58

Agroterrorism, European research, S44

Aguilar, E., 1338

Ahmad, K., S85, S137

Ahn, I.-P., 331

Ah-You, N., 1568

Aitken, E. A., S2

Akimitsu, K., 557

Akutsu, K., 712

Alabi, O. J., S3

Al Adawi, A., S27

Alarcón-Zúñiga, B., S108

Albano, J. P., S2

Albertazzi, F. J., 1338

Aldwinckle, H. S., S185

Alexander, B., S45, S86

Alezones, J. M., S173

Alfalfa, Verticillium wilt, quantifying with PCR assay, 1519

Alfano, G., 429

Alfaro, R., 1532

Alfenas, A., 1648

Al Habsi, N., S26

Ali, S., 1608, S3, S10, S15, S85

Al Jabri, S., S26

Aljaro, A., S101

Alldredge, J. R., S168
Allen, C., S23, S28, S75, S77, S127, S148

Allen, R., S146

Allen, T. W., S124

Allium sativum, seed survey, S167

Al Maqbali, Y. M., S26

Almeida, R., S3, S57

Almenar, E. S3

Almeyda-Becerra, C., S3

Al-Niemi, T., S3, S115

Alnus glutinosa, Phytophthora-induced decline, France, 99

Alrwahnih, M., S4

Al Sa'di, A. M., S2, S26

Al-Said, F. A., S2

Alternaria spp.

-A. alternata: on apple, core rot, postharvest, 1415; on lemon and tangerine, pathogenicity, S79; on melon, Maryland, S130; on pistachio, fungicide resistance, $\mathrm{S} 5$

-A. brassicicola, gene Asol, pathogenicity on cabbage, $\mathbf{S 7 8}$

-A. citri: in citrus, gene overexpression, 557; on orange, overexpression mutant, cover photo, May

-A. dauci, on carrot, intraspecific variation, $\mathrm{S} 100$

-A. solani, on tomato, QoI fungicide resistance, S87

Altier, N., S91

Alvarez, A., S51, S60, S89

Alves, E., S63

Al Yahyai, R., S27

Amari, K., 892

American Phytopathological Society

—annual meeting abstracts, July supplement, S1

—annual report, 17

- Award of Distinction, 28

—cacao disease symposium, 1634, 1640, 1644, $1648,1650,1654,1658,1664$

—Caribbean Division abstracts, 2006, S173

-Excellence in Extension, 29

-Excellence in Industry Award, 30

-Excellence in Teaching Award, 31

-Fellows, 19

-International Service Award, 32

- Lee M. Hutchins Award, 33

- North Central Division abstracts, 2006, S159

—-Northeastern Division abstracts, 2006, S177

—officers, representatives, and committees, 14

-Pacific Division abstracts, 2006, S166

-Potomac Division abstracts, 2007, S184

-Ruth Allen Award, 34

- Southern Division abstracts, 2007, S180

- Special Session Presentation abstracts, S131

—symposium, 221, 227, 233, 239, 244, 250

- Syngenta Award, 35

-William Boright Hewitt and Matbelle Ellen Ball Hewitt Award, 36

Ames, K. A., S13

Amil, A. F., 1451

Amiri, A., 1376

Amores, F. M., 1664

Amorim, L., 674

Ampong-Nyarko, K., S49

Amzalek, E., 179

Anagnostakis, S. L., S112

Anand, A., S4

Anchieta, A. G., S124

Anderson, K. L., S42

Anderson, P. A., 650

Anderson, R., S184

Anderson, S. J., S4

Andrade, M., 544

Andreasen, V., 1325

Andreu, A., S62, S112
Andrie, R. M., 694

Andrivon, D., 338

Angel, C. A., S7

Anisogramma anomala, on filbert:

— genetic diversity, S177

—variability, S8

Ansari, K., S13, S33

Antal, Z., 532

Antibiotic, patulin, fruit juice, Italy, S44

Antoun, H., S178

Aoun, M., S4

Aphanomyces cochlioides

—on sugarbeet, field distribution, S56

- survival dynamics, oospores and heat stress, 484

Appel, D., S42, S46

Apple

-Alternaria alternata, core rot development, 1415

-brown rot: injury and environment, Hungary, S47; management and dropped fruit, 1104

- 'Candidatus Phytoplasma mali', virulence and genomics, 964

- fire blight: forecasting, model, 1164; pathogen survival on fruit, 1263; Prohexadione-calcium effect, S74; warning system, letter to editor, 1036

— genomic analysis, fire blight, S185

-Penicillium expansum, on apple, gluconic acid and glucose oxidase effect, 384

—replant disease, etiology in South Africa, S114

- scab: epidemics and cultivars, organic production, S47; fungicide and adjuvant applications, S32; myclobutanil sensitivity, Virginia, S185; spatial heterogeneity, sampling plan, S177

- sooty blotch and flyspeck: biogeography, S28; Iowa, S108; Koch's postulates, S46; reservoir hosts, S46; warning system, Midwest U.S.A., S30

- Sphaeropsis rot, infection timing in orchard, S57

- training system, epidemiology factors, S83

-Venturia inaequalis, appressorium melanization, pathogenicity requirement, 1222

Apple latent spherical virus, Bean yellow mosaic virus coinfection, on Chenopodium quinoa, analysis, 1200

Apple stem grooving virus, on pear, Taiwan, S125

Apricot, pollen grain, Prunus necrotic ringspot virus effect, 892

Aqeel, A. M., S159

Ara, J., S31, S112

Arabidopsis

—defense signaling transduction, actin, S114

-Hyaloperonospora parasitica, immune responses, S58

Arabidopsis thaliana

-disease resistance, transcriptional regulator, S115

—rhizosphere and phyllosphere, resistance, S7

Aradhya, M. K., S58

Arango, C. M., S173

Arayam, C., S101

Archibald, D. D., 504, S52

Ardila, H., S173, S174

Arias, C., S87

Arida, D., S149

Armillaria sp., on cherry, resistance evaluation, S48

Armstrong, R., S28

Aroian, R. V., S144

Arredondo, F., S146

Arzanlou, M., 1112 
Ascochyta rabiei

- on chickpea, azoxystrobin and pyraclostrobin sensitivity, S124

— sensitivity to fungicides, S165

Ashizawa, T., 598

Aspergillus spp.: ferulic acid, S102; identification using rep-PCR, S88; on maize, Section Flavi communities, S94; ochratoxin A, phenolic antioxidants, S89

-A. flavus: aflatoxin contamination, management, S169; aflatoxin gene cluster, recombination, S79; aflatoxin genes, Mississippi, S1; aflatoxin and oxidative stress, S109; aflatoxin protein, conservation, S55; borate response, S93; commercial production, mutants, S169; copper tolerance, S25; on corn, Texas and Mexico, S22; on cotton, biocontrol, S168; L and S strains, diversity in Texas and Arizona, S172; on maize gene expression during pathogenesis, S29; on maize ears, resistance, mycotoxins, 311; on maize kernels, genes, S56; on maize kernels, protein and resistance, 1094; mutants, differentiation, S73; oxylipin signaling, S48; spatial variation, field population, S51

-A. fumigatus, vegetative compatibility, S166

-A. parasiticus, A. flavus comparison, aflatoxigenicity, S96

Asselin, J. E., S4

Astragalus utahensis, Alternaria and Aspergillus spp., environment relation, S32

Atallah, Z. K., 865, S4, S5, S40, S162

Atiri, G. I., S86

Atkinson, H., S108, S144

Atkinson, L. M., S5, S80, S161

Aubertot, J., S91, S92, S137

Auras, R. A., S3

Austerweil, M., 1476

Austin, C. N., S5

Author index to meeting abstracts, S187

Avant, J. B., 1063

Avanzato, M., S5

Avelino, J., 1532

Avenot, H. F., S5

Avery, D., S135

Avila, L., S5

Avila-Quezada, G. D., S6

Avocado, anthracnose, Mexico, S6

Azad, H., S46, S107

Babadoost, M., S6, S33

Bacetty, A. A., S6

Bacillus spp.

-B. mojavensis: fungitoxin from corn, effect, S6; on maize, phenotypes, S87

-B. mycoides, biocontrol agent, commercialization, S50

Backus, E. A., S6

Bacon, C. W., S6, S87, S88

Bacon, R., S17, S18, S23

Bacteria

— detection using mass spectrometry, S94

-diffusible signals in communication, symposium, 227

— growth promoting and nodule producing, fungi and nematode management by, S31

Bacteriophage

— citrus canker, Florida and Argentina, S8

- disease control and multiplication ability, S7

Bae, J., 865, S4

Bae, Y., S57, S108

Bahri, B., S6

Bai, J., 1083, S36, S150

Bai, X., S29, S64

Bailey, A., S12

Baird, J., S75

Baker, A. H., S125

Baker, C. A., 145, S2

Baker, K. M., S7, S122

Baker, R. L., S7
Bakker, P. A. H. M., 239, S7

Balaji, B., S7

Baldo, A. M., S185

Baldwin, C., S94

Ballard, K., S19, S83

Balmas, V., 1434

Balogh, B., S7, S8, S121, S141

Baltazar, A., S149

Banana

—black leaf streak disease, virulence assay, 916

—black sigatoka: phyllosphere bacteria, S175; QoI sensitivity, Costa Rica, 1451

-finger-tip rot, molecular typing of strains, Taiwan, 195

- Sigatoka disease complex, molecular diagnostics, 1112

Banana streak virus, badnaviral integrants, resistance, S67

Bancroft, T., S84, S117

Bandyopadhyay, R., S3, S14, S148

Banihashemi, Z., S8, S79, S80

Baquero, B., S173

Barak, J. D., S139

Barbetti, M. J., 1011

Barboza, B., 1532

Barker, I., S44

Barley

-Fusarium head blight and mycotoxin, infection timing, 1054

-leaf blotch, PCR detection, epidemics, 297

-leaf rust: metabolism inhibition, 1578; resistance gene, S112

-net blotch: molecular markers, 842; proteinaceous metabolites, symptom effect, 907

- root rot, agents in Russia, S57

- scald, asexual genetic exchange, 650

-Septoria speckled leaf blotch: population genetic structure, 938; resistance, 155; sequence tagged site markers, 162, 538

-spent anther extrusion, cover photo, September

— spot blotch and root rot, resistance, S12

- stripe rust, recessive resistance gene, mapping, 668

Barley mild mosaic virus, strain analysis, Korea, $\mathrm{S} 53$

Barley yellow dwarf virus

- Cereal yellow dwarf virus comparison, genome diversity, S77

-host alternations, S27

- on wheat, resistance sources, S27

Barman, S. R., S54

Barnes, C. W., 717, S8, S113

Barnes, I., 825

Baron, J. J., S13

Barquero, M., 1532

Barreto, S. S., S91

Barrientos, V. R., S173

Barriga, C., S8

Barthelson, R., S121

Bartlett, D. W., S161

Bartz, F. E., S8

Bartz, J. A., S8, S69

Basart, J., S85

Bassanezi, R. B., 674

Bassett, C. L., S185

Bates, C., S47

Batzer, J. C., S28, S46, S108, S113

Baughman, T. A., S183

Baum, T., S117, S126, S144, S145, S156

Baumber, R., S146

Baxer, S. N., S8, S177

Baxter, L., S146

Bayrak, O. F., S103

Baysal, F., S9, S9

Bean, T. P., S9

Bean common mosaic virus

- Blackeye cowpea mosaic virus, infecting strain, on cowpea, diagnosis, 1526

—diagnosis, S48
Bean pod mottle virus

-bean leaf beetle relation, S110

- genetic reassortment, 79

- RNA1 recombinants, molecular characterization, 1255

-on soybean: host pathogen interaction, S129; insects, S78; symptoms, cover photo, January

-temporal and spatial patterns, Iowa, S160

Beard, G. H., S9

Beasley, J. P., S87

Beattie, A. D., 842

Beattie, G. A., S20, S36

Beauveria bassiana, bacteria for control, S162

Becker, E., S166

Becker, J. O., S154

Beckerman, J., S27, S159

Beckett, R. J., S77

Beede, R. H., S104

Been, T. H., S152

Beer, S. V., S4, S11

Beet black scorch virus, characterization, U.S. isolate, 1245

Beet necrotic yellow vein virus

-resistance-breaking isolates, TaqMan technology, 325

-resistance-breaking strain, S170

-rhizomania case, resistance durability, S2

-on sugar beet: storability, S111; suppression by

Beet oak-leaf virus, S65

Beet western yellows virus, on spinach, S30

Beever, R., S12

Bekele, S., S144

Belanger, R. R., S42

Belausov, E., 1491

Bell, A. A., S65

Bellafiore, S., S9

Bemisia tabaci, cucurbit vine decline transmission, 145

Bender, C. L., S120

Benitez, M.-S., 756, S9

Bennet, R., S150

Bennett, C. M., S17

Bennett, R. S., 584, S10

Béno, N., 611

Benson, D. M., S98

Benson, J., S10

Benson, M., S125

Bentley, S. D., S11

Bentley, T., S30

Bergamin-Filho, A., 674

Berger, P., S147, S151

Bergstrom, G. C., 584, S125, S140

Berk, S. G., S141

Berkelmans, R., S154

Bernad, L., 1004

Bernal, A. J., S8, S118

Bernard, G. C., S10

Berner, D. K., 997, S59

Bernier, L., 603, S4

Berry, S. A., 106

Bertrand, F., S38

Betrán, J., 311

Beynon, J., S146

Bhakta, V. G., S28

Bhanupriya, M., S97

Bhat, R. G., S10, S104, S111

Bhattarai, K. K., S70

Bian, X.-Y., 930

Biggs, A. R., 1164

Bilgi, V. N., S10

Bilgrami, A. L., S133

Billing, E., 1036

Bilodeau, G. J., 632, S10

Bing, D., S20

Biological control

-Cryptococcus laurentii on jujube fruit, glucanase genes, 260

-entomopathogenic nematodes, spatial ecology, S143 
-Fusarium oxysporum and Pseudomonas sp. shelf life in talc and charcoal, S55

- Phytophthora nicotianae on Phytophthora spp. on citrus, 958

-Piriformospora indica on wheat, greenhouse and field, 523

-Pseudomonas spp.: on rhizosphere, colonization 756; symposium, 221, 227, 233, 239, 244, 250

-root weevil in citrus, Florida, S142

- seed meal amendment, pathogen suppression in Brassica, 454

— soil solarization and organic amendments, 1476

-Trichoderma spp., for cotton damping-off, fungicide combination, 66

-Trichoderma hamatum for Xanthomonas euvesicatoria, 429

— trophic cascades: S143; spatial variation, S142

Birch, P., S146

Bird, G. W., S148

Bird, J., S14, S174

Bisaro, D. M., S154

Bittner-Eddy, P., S146

Black, M. C., S183

Black, S., S19

Blackberry, virus, new in Mississippi, S102

Blackberry chlorotic ringspot virus, Strawberry necrotic shock virus comparison, nucleotide sequence, $\mathrm{S} 116$

Blackburn, N. J., S104

Black raspberry necrosis virus, on Rubus occidentalis, detection, 44

Blaedow, R. A., S10

Blair, J., S157

Blanchard, A., S103

Blanchette, R. A., S91

Blanco-Meneses, M., S11

Blaxter, M., S132

Blein, J.-P., 611

Blin, L., S94

Bliss, T. J., S158

Block, C. C., S11, S35

Blok, W. J., S106, S154

Blomquist, C., S101, S105, S126

Blueberry, virus-like diseases, protocol for RNA extraction, S71

Blumeriella jaapii

- on cherry, survival analysis, S83

- copper fungicides, photosynthesis, S43

Blunt, T. D., S11

Bock, C. H., S11

Bockelman, H., S60, S151

Bocsanczy, A., S11

Boddeda, A., 835, S160

Boehm, M. J., 170, S9, S53, S104, S134

Boerma, R., S114

Bogdanove, A., S84

Boine, B., S12

Boivin, G., S177

Bok, J., S55

Boland, R., S20

Bollich, P., S82

Bolognesi, M., 352, 1625

Bonants, P. J. M., 1119, S12

Bonde, M. R., 997

Bonifert, M., S44

Bonman, J. M., 1063, S151

Bonn, G., S105

Bonos, S. A., S177

Boore, J. L., S4

Boovaraghan, B., S114

Borejsza-Wysocka, E., S185

Borneman, J., S154

Borsick Herman, M. A., S12

Borth, W., S68

Borthakur, D., S60

Bos, J. I. B., 429, S145, S146

Boso, S., 780

Bost, S. C., S12

Bostock, R. M., 269, S29, S126, S166
Botrytis cinerea

—on ginseng, benzimidazole resistance, S57

-on grape: elicitin, Pythium strain, 611; fenfexamid for control, S130

-hypovirulence, RNA, 1590

-molecular ecology, S96

- on strawberry: fungicide resistance, S36; fungicide and rotation programs, California, S111

- on tomato, resistance affected by elicitor, S163

- virus X, RNA extraction, S12

Boudon-Padieu, E., 72

Bourassa, M., 603

Bousset-Vaslin, L., S91

Boveri, M., 1422

Bovill, J. H., S12

Bovill, W. D., S12

Bowden, R. L., 1083, S150

Bowen, K., S17, S24, S87, S112

Bowers, J. H., 492

Boyette, C. D., S13, S121

Boyham, G., 1298

Brachiaria sp., endophytic bacteria, growth enhanced, S55

Bradley, C., S10, S13, S50, S124, S125, S165

Bradshaw, R. E., 825

Bragg, J. N., S38

Brand, M., 813

Brandl, M. T., S141

Brandt, A. S., S16

Brandt, N. R., S13

Brannen, P. M., 1376, S13, S20

Brassica spp.: pathogen suppression by seed meal amendment, 454; root knot nematode, suppression, S110

-B. napus: blackleg, spore discharge, Australia 1011; Sclerotinia stem rot, forecasting model, 1186; Verticillium wilt, interspecific hybridization, 1391

Braverman, M. P., S13

Bremer, D. J., S36

Bremia lactucae

-on lettuce, sporulation factors, 979

- sporophores and spores, cover photo, August

Brennan, J. M., S13, S29

Brenneman, T. B., S50, S180, S181

Brenneria rubrifaciens, on walnut, pigment regulation, S73

Bressan, A., 72

Bretting, P., S150

Breuer, Jane, 1150

Breuer, Jeffrey, 1150

Breuil, C., 1040, 1177

Breukers, A., 945

Brière, S. C., 632, S179

Briggs, S., S9

Brlansky, R. H., S173, S174

Broders, K. D., S14, S159

Brome mosaic virus, gene silencing induced by, on rice and grasses, $\mathrm{S} 83$

Bronson, C. R., S113

Brooks, S. A., 1207

Brown, A. V., 825

Brown, D. E., S75

Brown, J. (Idaho), 454

Brown, J. K. (Ariz.), S14, S46, S49, S116, S124, $\mathrm{S} 174$

Brown, J. S. (Fla.), 1664

Brown, L. G., S105

Brown, P. R., S30

Brown, R. L., 1094, S7, S14

Brown, S. L., S87

Browne, G. T., S10, S14, S104, S111

Brown-Guedira, G., S33, S150

Bruce, C., S146

Bruckart, W. L. (Md.), S19

Bruckart, W. L., III (Va.), S184

Bruening, G., S14

Bruening, P. A., S14

Bruhn, J., S94
Brunk, G., S11

Brunner, P. C., S128

Bruns, A. H., S1

Bruton, B., S99, S182

Bryan, B., S2

Bryson, P. K., 448, S25

Büche, C., 780

Buchmann, R. C., S154

Buck, J. W., S85, S125, S159, S182

Buckles, G., 1558, S36

Buda, G. J., S81

Buechley, G., 1608

Buell, C. R., S14

Buell, R., S61

Buigut, J., S121

Buitrago, G., S174

Bull, C. T., S98, S166

Bulluck, R., S151

Burch-Smith, T., S145

Burgers, S. L. G. E., 971

Burgos, L., 892

Burkett-Cadena, M., S180

Burkholderia spp.: antifungal activity, genes, S67; ecological niches, S139; in soil, analysis in North Carolina farms, S66

- B. cenocepacia, on banana, molecular typing, Taiwan, 195

-B. glumae, on rice, partial resistance, $\mathrm{S} 82$

Burlakoti, P., S15, S56, S160

Burlakoti, R. R., 835, S15, S160

Burnett, A., S15, S177

Burpee, L. L., S85, S182

Burr, K., S128

Burr, T., S18, S25, S26, S177

Burrows, M. E., S15

Bursaphelenchus xylophilus, on pine, genetic structure of populations, 304

Buruchara, R., S69

Bush, E. A., S185

Bushe, B., S97

Buss, L., S88

Bustamante, E., S175, S181

Bustillos-Cristales, R., S70

Butterworth, S. C., 737

Byamukama, E., S68, S110, S160

Caasi, O. C., S16

Caballero-Mellado, J., S70

Cabut, S., 1532

Cadavid, M., S16

Cadle-Davidson, L., S16, S39, S40, S119

Cadle-Davidson, M., S119

Cadophora gregata, on soybean:

- South Dakota survey, S162

-yield and quality, S113

Caenorhabditis elegans, WormBase, WormBook, and Textpresso, S157

Caesar-TonThat, TC., S169

Cai, G., S16

Caicedo, O., S174

Cain, S., S47

Cakir, C., 429, S16, S146

Calcote, J. L., S16

Caldiz, D. O., S62

Caldo, R., S84

Callan, B., S179

Camacho-Casas, M., S37

Camberato, J. J., S122

Camilli, K., S17, S46

Camp, A., 756

Camp, S., S111

Campbell, H. L., S17, S44

Campbell, K., S114

Canaday, C. H., S181

Canady, M., S34

Candelaria, N., S19

Candidatus Liberbacter spp.: on citrus, molecular technique for cloning, S64; detection in hosts, PCR, S64 
'Candidatus Liberbacter asiaticus': on citrus, detection, S106; on periwinkle, DNAs from, S27

'Candidatus Phytoplasma mali', on apple, genomic features, 964

Candole, B., S17

Canola

- diseases, systemic acquired resistance, salicylic acid, 794

_durable resistance, modeling, S91

-Phoma stem canker, severity, S137

Cantaloupe, powdery mildew, fungicide efficacy, Arizona, S71

Cantonwine, E. G., 187

Cao, T., S17

Capsicum spp., Pepper mild mottle virus, coat protein, 787

-C. annuum: Pepper golden mosaic virus, resistance and symptom remission, 51; Phytophthora capsici and Verticillium dahliae on, interaction, 37; powdery mildew, microclimate, 813

Carbone, I., 470, S11, S79, S96

Cardwell, K., S61

Carisse, O., S17, S18, S177

Carlier, J., 1112

Carnation, Fusarium wilt, enzyme chemistry, S175

Carnevali, G., S46

Carpane, P. D., S18

Carrillo, G., S18

Carrillo-Tripp, J., 51

Carroll, J., S18, S177

Carrot, black rot, phylogenetic relations of species, S90

Carson, M. (Minn.), S18

Carson, M. L. (N.C.), 1501

Carta, L., S82, S152

Cartinhour, S. W., S11

Cartolaro, P., S123

Caruso, F. L., S18, S93

Casler, M., 767

Castañeda-Lucio, M., S70

Catal, M., 737

Catcheside, D. E. A., 907

Cavin, C. A., S19

Cawly, J. D., S7

Cela, S., S136

Celery

—early blight and basal stalk rot, management, S95

- Septoria late blight, calcium suppression, S115

Cepero de García, M., S5

Cerasus spp., decay fungi, streets in Japan, S108

Ceratocystis spp.

-C. fagacearum, on oak, clones and half-sib families, S42

- C. fimbriata, on mango, resistance, $\mathrm{S} 27$

Cercospora spp.

$-C$. arachidicola, on peanut, strip tillage effect, 187

-C. beticola: on safflower, leaf spot, S169; on sugar beet, epidemiology and modeling, 1550

-C. kikuchii, on soybean, linoleic acid ratios, S117

Cereal

- Heterodera and Meloidogyne spp., phosphite inhibition, 396

-Rhizoctonia root rot, damping-off and bare patch, PCR assay, S170

Cerón, L., S174

Cha, J., S52

Chacón, C., 1338

Chaijuckam, P., S19

Chain, F., S27

Chaluvadi, S. R., S19, S83

Chamaecyparis lawsoniana, Phytophthora lateralis, histopathology and resistance, 684

Chambers, A., S19

Chambliss-Bush, S., S19

Chan, C.-W., 195

Chan, Z. L., 260
Chanda, A., S19, S90

Chandra-Shekara, A., S54

Chanemougasoundharam, A., S13

Chang, C., S20, S67, S121

Chang, K., S20

Chang, M., S20

Chang, P. G., S184

Chang, S., S52

Chao, D., S138

Chapara, V., S160

Charkowski, A. O., 1150, S50, S71, S127

Charudattan, R., S107

Chase, T. E., S20

Chassaigne, A. A., S173

Chastagner, G. A., 551

Chau, J. H., S3

Cheah, K., S108

Cheatham, M. R., S102

Chellemi, D. O., S20

Chen, C. (Iowa), S20

Chen, C. (Calif.), S21

Chen, C. J. (China), 1584

Chen, F., S42

Chen, H.-M., 900

Chen, J., S21, S22, S27, S67, S75, S172

Chen, K., S35

Chen, L.-F., S154

Chen, M.-M., S138

Chen, P., S101, S107

Chen, R., S21

Chen, S., S112

Chen, W., S120, S165

Chen, X. M., 668, S21, S24, S166, S169, S171

Chen, Y. (China), 1584

Chen, Y.-R. (Taiwan), 900

Chen, Z.-Y., 1094, S7, S14, S19, S90

Chenault, K. D., S22

Chenopodium quinoa, Apple latent spherical virus and Bean yellow mosaic viruses coinfection, fluorescent proteins, 1200

Cherry, K. R., S38

Cherry necrotic rusty mottle virus, characterization, Japan, S64

Cherry rasp leaf virus, on potato, picorna-like virus primers, $\mathrm{S} 113$

Chestnut, blight, polyketide synthase gene and gene disruption, $\mathrm{S} 112$

Chi, T., S21

Chickpea, Ascochyta blight, fungicides, S171

Ching-Yi, L., S22

Chiroleu, F., 1568

Chitrampalam, P., S22

Chitwood, D. J., S152

Cho, J. Y., S22

Cho, Y., S100

Choi, H., S48

Chong, J., 1063

Chriscoe, S. M., S184, S185

Christ, B. J., S123

Christiano, R. C. S., 1428, S22

Church, G., S20, S101

Churchill, A. C. L., 916, S112

Ciavorella, A., S44

Cicer arietinum

-Ascochyta blight, ascospore and conidial germination, differences in chickpea, 1600

-Fusarium wilt, races 0 and 5 , temperature and inoculum density effects, 564

Cilas, C., 1532

Ciotola, M., S23

Citrus

-bacterial diseases, new in Florida, S30

—black rot, gene overexpression, 557

- canker: ImmunoStrips for confirmation, S97; leafminer gallery, cover photo, June; spatial pattern analysis, Asian leafminer, Brazil, 674; survey in Florida, S90; symptom assessment, S11

-disease resistance, broad spectrum, S60
- disease status in Kenya, S121

- exotic diseases, Caribbean, S173

- greening: functional genomics, S120; management practice, psyllids, S70

- greening disease: genomics and phylogenetic analyses, S29; psyllids for identification, S70

- greening and psyllid vector, Texas, S25

—-huanglongbing disease, in psyllids, Florida, S96

-NPR1 defense gene family, S35

-Penicillium digitatum, hydrogen peroxide suppressed in host tissue, 1491

-Phytophthora spp., isolate competition, 958

Citrus exocortis viroid

-on tobacco and citrus, intra-population profile, S44

—Vicia faba isolate, properties, 1004

Citrus triteza virus

—classification with proteins, S175

-on Poncirus trifoliata, resistance, S45

—RT-PCR assay, S104

- serology, Colombia, S175

- strains, recombination, S121

Ciuffetti, L. M., 694

Ciuffo, M., S98

Civerolo, E., S14, S21, S27, S29, S64, S67

Clark, C., S23, S74, S76, S181

Clarke, B. B., S25, S178

Clarke-Harris, D., S148

Clarkson, J. P., 621

Claviceps purpurea

- ecological speciation, S30

- peptide synthetase, modular nature, S102

Clayton, M. K., S5

Clement, P., S109

Cleveland, T. E., 1094, S7, S14

Clifford, J., S23

Cloud, G., S170

Clough, G. H., S167

Clover yellow vein virus, on pea, protein-tagged virus, 544

Coates, M., S146

Cobb, J. N., S23

Cochliobolus spp.

- C. heterostrophus, race T, polyketide T-toxin, S49

-C. miyabeanus, on rice, morphogenesis, calcium effect, 331

Cochran, A., S45, S170

Cochran, K., S114

Coconut, lethal yellowing:

- Central America and the Caribbean, S100

- status in Mexico, Central America, and Caribbean, $\mathrm{S} 176$

Coffee, leaf spot epidemics, management factors in Costa Rica, 1532

Coffey, M., S23, S39, S91, S157

Coffman, G., S170

Coffman, V. A., S94

Coggeshall, A., S166

Cohen, L., 1491, S69

Cohen, M. F., 454, 1348, S72

Cohen, Y., 179, 1274

Colbert, T. R., S149

Colburn, G. C., 958

Cole, D., S49

Coletta-Filho, H., S106

Coleus, downy mildew, management, S178

Colgrove, A. L., S23

Collazos, J. C., S175

Colletotrichum spp.: on grasses, mating-type gene cluster, S25; on hot pepper and fruit, Korean isolates, S48; on Korean ginseng, S108; on olive, plant parts infected, S79; tropical fruits, genetic diversity in Colombia, S16

-C. acutatum: on fruits and ornamentals, host range, S69; on lulo fruit, enzymes, S175; on pepper, wound periderm, S57; on strawberry, detection assay, S82; on strawberry, PCR assay, S82 
-C. cereale: azoxystrobin resistance, S128; transposons and sex, S178

-C. coccodes, azoxystrobin sensitivity, S159

-C. gloeosporioides: on citrus, mating behavior, $\mathrm{S} 79$; on strawberry, native plant populations, 1130

-C. graminicola: on maize, fiber cell colonization, 438; on turfgrass, fungicide, New England, S78

-C. orbiculare, on cucurbit or weed hosts, species comparisons, factors, 1305

- C. truncatum, host specificity, $\mathrm{S} 42$

Colucci, S. J., S24

Colyer, P. D., S10

Compost, soil-borne pathogen control, horticulture use, S95

Concelmo, D. E., S8

Conifer

- annosus root rot, Christmas tree plantations, Pacific Northwest, 551

- salt effect, Lake Tahoe Basin, S17

Coniothyrium minitans

- conidial production, culture on rice and cornstalks, S66

- pH effect, S162

- Sclerotinia sclerotiorum comparison, sclerotial treatment, S22

- on snap bean, biocontrol agent, Wisconsin, S63

Conn, K. L., 1071

Connell, J. H., S17

Conner, K. N., S24

Conner, P., S17

Contero, L., 1356

Conway, W. S., S51

Cook, A. Z., S11

Cook, C., S88

Cook, R. D., 484

Cooke, D., S79, S80

Cooksey, D. A., 857, S46, S107

Cooley, D. R., S177

Cooley, M. B., S138

Cools, H. J., S9, S24

Coomans, A., S133

Coop, L., S24, S92

Cooper, B., S43, S114

Copes, W. E., S181

Coram, T. E., S24

Corbière, R., 338

Corn (see also Maize)

- Aspergillus flavus and Fusarium moniliforme, mycotoxin and fatty acid content, correlation, S173

- ear rot and aflatoxin, resistance sources, S7

-mycotoxins, plant debris, S1

-stunt, management, S167

Cornus florida

—dieback and decline, fungi, S78

-root endophyte, seedling colonization, S80

- seed-borne fungi, S85

Correa Victoria, F. J., S24

Correll, J. C., 1305, S25, S118

Cortez, A. A., S124

Corwin, J., S179

Corynespora spp., host range, phylogenetic analysis, S109

Costa, H. S., 857

Costa, S., S157

Costanzo, S., S123

Costello, J., S111

Costello, L. R., S101

Côté, M.-J., S152

Cotton

-aflatoxin biocontrol agent, pyrosequencing, S26

-damping-off, seed treatments, 66

-flower infection, Fusarium spp., S63

-Fusarium hardlock, management in Florida, S63

-Fusarium-infected seed, heat treatment, S10

-nematode and fungus interaction, soil texture, S51
Cotty, P. J., S22, S25, S26, S39, S51, S73, S88, S93, S94, S166, S168, S169, S172

Coughlan, S., S86

Covello, P. S., 794

Cover photo

-Alternaria citri, on orange, overexpression mutant, May

- barley, anther extrusion, spent, September

- Bean pod mottle virus, on soybean, symptoms, January

-Bremia lactucae, sporophores and spores, August

- citrus, canker, leafminer gallery, June

- grape: Plasmopara viticola, symptoms, July; powdery mildew, insect feeding, October

- Phytophthora capsici, on pear, use as bait, April

- Phytophthora palmivora, pod rot, December

-Verticillium longisporum, symptoms, on Brassica napus, November

-watermelon, vine decline symptoms, February

-Zucchini yellow mosaic virus, cross protection, March

Covert, S. F., S55

Cox, K. D., 448, S25, S27

Coyne, C., S151

Cozijnsen, A. J., 879

Cranberry

-disease in Massachusetts, S18

-fruit rot complex, population, $\mathrm{S} 93$

Crane, C., S128

Craven, K. D., S78

Creasap, J. E., S25

Creaser, M. L., 1284

Crescenzi, A., S98

Crisosto, C. H., S126

Crisp, G. R., S25

Cronartium spp.

- C. quеrcuum: on loblolly and slash pines, tissue repair, S119; on longleaf pine, seedling infection, S183

-C. ribicola: genome size, basidiospore cytometry, S128; on white pine, resistance genes, 728

Cropping systems, organic, disease suppression, S71

Crop sequence, peanut, cotton, and corn, irrigation system, Alabama, S17; soil microbial effect, S87

Crosslin, J. M., S166

Crouch, J., S8, S25, S177, S178

Crous, P. W., 825, 1112

Crow, W. T., S88, S158

Crucifer

—bacterial blight, California, S166

-black rot, genetic diversity in California, 803

Crump, N. S., 1071

Cruz, C., S100

Cryphonectria parasitica, virulence, silencing, $\mathrm{S} 50$

Cryptococcus laurentii, on jujube, biocontrol, 260

Csinos, A., S17, S84, S181

Cubeta, M. A., S8, S109

Cucumber

-damping-off, interaction in Oman, S26

—pathogens resistant to QoI fungicides, 1458

-Pythium damping-off, planting treatment and metalaxyl, S2

Cucumber mosaic virus

—heirloom species isolates, Virginia, S184

—on spinach, S30

Cucurbit

- powdery mildew: fungicide and cultivar, S179; fungicides, $\mathrm{S} 2$

—vine decline, Potyviridae, transmission, 145

Cucurbit yellow stunting disorder virus, on melon,

U.S.A. and Mexico, S124

Culbreath, A. K., 187, S181

Cunfer, B. M., 584

Cuomo, C., S113

Cuppels, D. A., S132

Curry, K. J., S180, S182
Cursino, L., S26

Curtobacterium flaccumfaciens, on bean and soybean, wilt, S161

Cvrkovi, T., S54

Cylindrocarpon destructans, on ginseng, periderm formation, S57

Cylindrocladium spp.

-C. crotalaria, on peanut, biocontrol with actinomycetes, S32

-C. parasiticum, on peanut: resistance, S181; resistance screening, S183

Cymbidium mosaic virus, on orchid, detection with ELISA kit, S97

Cyrtomium falcatum, virus, S117

Cytoplasmic citrus leprosis virus, genome sequence, $\mathrm{S} 174$

Czarnecki, J., S9

Daane, K., S108

Dactylaria higginsii, bioherbicide for nutsedges, S107

Da Graça, J., S25

Dai, Y., S25

Dalbulus maidis, on corn, resistance evaluation, S18

Dale, A., 825

Daleo, G., S112

Daly, C., S92

Damann, K. E., 1094

Damicone, J. P., S25

Damsteegt, V. D., S26

Dangl, J., S71

D'Arcy, C. J., S26, S31

Dart, N. L., 551

Das, M. K., S26

Date, H., 1458

Datnoff, L. E., S34, S109

Daughtrey, M. L., S178

Davelos Baines, A. L., S39, S102

Davey, J. F., S73, S178, S179

David, N. L., S167

Davidson, J. M., S36

Davis, E. (USDA-APHIS-PPQ), S151

Davis, E. L. (N.C.), S49, S98, S126, S144, S156

Davis, M., S12

Davis, R. E., S53, S121

Davis, R. M., S19

Davis, W. C., S128

Dawson, T. E., S45

Dawson, W. O., S121

Day, A., 1356

Day, B., S114

Deadman, M. L., S2, S26, S27

Dean, R., S42, S75, S86, S113

De Barro, P. J., 930

Declerck, G., S11

de Cock, A. W. A. M., 632, S10

Decraemer, W., S133

Deford, R., S27

de Gruyter, J., 1119

de Haas, B. H., 971

Dehne, H., S44

Deising, H. B., 523

de la Cerda, K. A., 857, S21, S26

Deladenus siricidicola, on Amylostereum, wood decay, $\mathrm{S} 123$

De La Fuente, L., S26

Delaunay, A., S27

De Ley, P., S133

Delmotte, F., S123

Del Ponte, E., S33

del Río, L. E., S95, S128, S161, S162, S164

del Río, M., S89

Dematheis, F., 987

Dendroctonus ponderosae, Ophiostoma clavigerum association, genetic diversity in British Columbia, 1177

Deng, M., S38

Deng, X., 260, S27 
Denitto, G., S41

Denno, R. F., S142

Denny, T. P., S28, S66

Derie, M. L., S30, S167

de Silva, A., S89

Desjardins, A. E., S51

Desjardins, Y., S42

Desmodium leaf distortion virus, new begomovirus, $\mathrm{S} 46$

De Vallavieille Pope, C., S6, S72

de Vries, I., 1112

DeVries, R. M., S129

Dewdney, M. M., 1164

DeWolf, E. D., 1608, S30, S33, S85, S123, S140, S147, S163

Deyholos, M., S107, S126

Dhar, A., S61

Dhulipala, M., S28

Diagnosis

-Bayesian approach, disease measurement, S69

- data collection, university, industry, government, S140

-Florida Plant Diagnostic Network, S88

- genome-based resource, threatened pathogen identification, S14

—plant virus, Primer3-mFOLD-BLASTn, S86

-Ramorum blight survey, SSCP, S179

Diagnostics, preparation, S135

Dianese, J. C., S91

Dias, A. S., S28

Diaz, G., S14, S61

Díaz Arias, M. M., S28, S46, S113

Dick, W. A., 756

Dickeya spp., host range and molecular phylogenies, 1150

-D. dadantii: virulence and biofilm formation, sigma factor, S50; virulence genes, hrp cluster, S127

Dickson, D. W., S158

Didymella spp.

-D. bryoniae, azoxystrobin sensitivity, South Carolina, S55

-D. rabiei, on chickpea, spore germination, 1600

Diesburg, K., 767

Dietrich, R. F., S28

Digennaro, P. M., S20

Diggle, A. J., 1011

Dileo, M. V., S29

Dillard, H. R., S107, S179

Dill-Macky, R., S39

Dinesh-Kumar, S. P., S145

Ding, X., S19, S83

Dingus, B. R., S184

Dioscorea spp., anthracnose, biochemical responses, $\mathrm{S} 174$

Diplocarpon rosae, on rose, resistance, S41

Diplodia spp., on red pine, conidial variation, S81

-D. pinea, on Pinus resinosa, shoot inoculum source, $\mathrm{S} 81$

Disease assessment

- predictive plant pathology, S137

- standard area diagrams, accuracy, S137

Disease information systems, internet-based, S140

Disease management, Graft-based Markov Decision Process, application, S92

Dixon, A. G., S3

Dixon, P. M., S30

Dixon, W. N., S135

Djavaheri, M., S7

Dmitriev, A. P., S163

Doddapaneni, H., S29, S64

Dodds, J. A., S131

Dolezal, A. L., S29

Dolezal, W., S18, S140

Dollet, M., S174

Domier, L. L., 366, S29, S114

Donahoo, R. S., 421, S78

Donald, P. A., S180

Donaldson, R., S20
Dong, S., S29

Dong, W. B., S181

Dong, Y., S1, S145

Donofrio, N., S86

Donzelli, B. G. G., 916

Doohan, F. M., S13, S29, S33

Doornbos, R., S7

Dorrance, A. E., 106, 113, 655, S9, S14, S78, S159, S160, S163

Doster, M. A., S169

Dothistroma septosporum, on pine, D. pini comparison, mating type genes, 825

Dou, D., S146, S184

Douglas, S. M., S179

Douglas-fir, Swiss Needle Cast, life expectancy, model, S24

Douhan, G. W., S21, S26, S30

Drader, J., S94

Draper, M. A., 211, S90, S162, S164

Dreher, T. W., S116

Drenth, A., S2

Driever, G., S36

Droby, S., 1491, S69

Druffel, K., S89, S103

Druzhinina, I. S., 532

Dry, I., S119

Duan, Y., S30, S85

Duchaine, C., 632

Dudley, N. S., S51, S168

Dufault, N. S., S30

Dugan, F. M., S165, S167

Dulla, G., S141

Dumenyo, C., S46, S107

Duncan, L., S142

Duncan, R. W., S30

Dunker, S., 1186

Dunkle, L. D., S128

Duran, C. M., S175

Durand, J.-F., 1532

Duran-Martínez, C. M., S174

Duran-Vila, N., 1004

Durr, E., S105

du Toit, L. J., S30, S34, S118, S167

Duttweiler, K. B., S30, S108

Duynslager, L., S122

Dweet mottle virus, on citrus, Citrus exocortis viroid comparison, $\mathrm{S} 155$

Dyer, A. T., 484, S47, S53, S111

Easley, S. A., S167, S170

Eastburn, D. M., S26, S31, S71

Eberle, M. A., S31

Echinochloa crus-galli, biocontrol, S59

Ecosystem services, plant pathology role, $\mathrm{S} 102$

Edmunds, B. A., S31

Edwards, M. C., 1245, S6

Egan, D., S13, S33

Eggenberger, A. L., S31, S129

Eggleston, G., S43

Eggplant (see also Solanum melongena)

— pathogens resistant to QoI fungicides, 1458

Ehlers, J. D., S80

Ehrlich, K. C., S26

Ehteshamul-Haque, S., S31, S112

Eick, A., 1491, S69

Eisenback, J. D., S31, S185

Ekramoddoullah, A. K. M., 728, 1406

Elad, Y., 813

Eldredge, S. D., S32

Elicitor, Oligandrin, Pythium oligandrum, grape gray mold, 611

Elkins, R., S38, S93

Elliott, G. C., S90

Ellis, M. A., S32, S97

Ellissèche, D., 338

El-Lissy, O., S151

Elm, Dutch elm disease, gene identification, S4

Elmer, W. H., S32, S178, S179

El-Metwally, M. A., S32
El-Sebai, O. I., S103

El-Sherif, E. M., S32

El-Tarabily, K. A., S32

Elwakil, M. A., S32

Elymus canadensis, endophyte, persistence, S128

Endophyte, maize and tomato inoculation, electron microscopy, S19

Engelbrecht, C. J., 1648

Engle, J. S., S33

English, J. T., S34, S43

Enjalbert, J., 1315, S6, S72

Enterobacter spp., on onion, leaf dieback in Washington State, S34

-E. cloacae, on papaya, internal symptoms, S84

Eocot, The Land, disease management, S49

Epidemics, two-parameter models, analysis, 1231

Eranthodi, A., S33

Erard, G. S., S33

Errata

—vol. 96, no. 11, 2006, 1243, 538

-vol. 97, no. 2, 2007, 162, 538

—vol. 97, no. 7 (Suppl.), 2007, 1376

—vol. 97, no. 7 (Suppl.), 2007, 1526

Erwin, D. C., S47

Erwinia spp., genetics of species, host specificities, S165

-E. amylovora: on apple, reaction to antibiotics, Utah, S34; on apple, secreted effector, translocation and chaperone interaction, S115; on apple and pear, forecasting with MARYBLYT and Cougarblight, 1164; on apple and pear, type III secretion islands, S129; biofilm formation, pathogenicity implication, S59; host specificity, Eop1 role, S4; on pear, persistence in fruit, $\mathrm{S} 171$; on pear, streptomycin resistance, California, S2; on pear, survival on fruit, 1263; on pear and apple, warning system, letter to editor, 1036 ; temperature, model, S95; virulence factors, bioinformatics, S11

-E. carotovora, on tomato, ferredoxin-I protein enhancement, 900

Erysiphaceae, host number increase, temperature, S175

Erysiphales, phylogenetic placement in Ascomycota, S65

Erysiphe spp.

-E. necator, on grape: conidia in canopy, S17; detection in air samples, 1290; epidemiology, S123

-E. pisi, on Medicago truncatula, resistance mechanisms, 1049

Escherichia coli, on spinach and lettuce, California, S138

Escuela Toruño, T., S176

Eskalen, A., S33, S38, S168

Eskandari, F. M., S184

Esker, P. D., S33, S102, S110, S147

Espeletia spp., biocontrol, endophyte, S5

Espinosa, A., S34

Esquibet, M., S103

Esquivel, C., 1532

Estrada, R. E., Jr., 835, S160

Ettedgui, Y., 1415

Eubanks, M. D., S81

Eucalyptus sp.

-Mycosphaerella leaf disease, PCR detection, 132

—pathogens, Uruguay, S91

Eulgem, T., S58, S115

Eutypa lata, on grape:

— climate effect on symptoms, 1284

-Eutypella vitis comparison, PCR for detection, 737

Evans, C. K., S34

Evans, H. C. 1640

Evans, R. G., S169

Evans, T. A., S185

Everts, K. L., 461, S130, S174, S176, S185 
Eynard, J., S92

Eynck, C., 1391

Fabre, F., 1484

Fagus sylvatica, Phytophthora canker, soil recovery, S83

Fakhoury, A. M., S7

Falacy, J. S., 1290

Falk, B., S4, S119, S155

Fallquist, H. M., S34

Fan, S., 405

Fang, G. C., S34

Fang, Z. D., S34, S43

Fares, S., S51

Farfán-Gómez, A., S108

Faris, J. D., 592, S66

Farmer, M.-J., 611

Farran, A., S114

Farrell, R. E., Jr., S185

Faske, T. R., S34

Feau, N., S35, S53

Febres, V. J., S35

Feil, H., 318

Feil, W. S., 318, S120

Fellers, J. P., 1083

Felts, D., S170

Feng, J., S35

Feng, S., S120

Feng, T.-Y., 900

Ferguson, L. M., 1501

Ferrandino, F. J., S178

Ferris, H., S142

Ferris, V., S158

Fessehaie, A., S35

Festuca arundinacea

- brown patch, digital analysis, S113

- gray leaf spot and brown patch, resistance, S29

- phylloplane, exogenous nutrients, S182

Fichtner, E. J., 1366, S36

Ficke, A., 1356

Fischer, W., S161

Fisher, K., S146

Fitch, M. M., S84

Fitt, B., S99

Flaherty, J. E., S128

Flaishman, M., 1415

Fletcher, J., S18, S44, S74, S75, S127, S139, S172

Fobert, P. R., 794

Food web, detrivorous arthropods, ecosystems, S176

Forest, exotic pathogens, prediction, S138

Forestry, tree shipments, international movement, S136

Forgan, A. H., 650

Forge, T. A., S142

Forseille, L., S42

Forsline, P. L., S51

Forster, H., S2, S36, S74, S111

Fortunella margarita, Xanthomonas axonopodis, on citrus, S56

Fory, P., S55

Foster, G., S12

Foster-Hartnett, D., S103

Fountaine, J. M., 297

Fox, A., S24, S92

Fraaije, B. A., 297, S9, S36

Francis, M., S14

Frank, E. E., S36

Frate, C. A., S167

Frati, S., S44

Frederick, R. D., 997, S4, S9, S76, S117

Freeman, B. C., S36

Freeman, T. A., 1331

Freeman, T. P., 1245

Freesia, leaf necrosis, S74

French, J., S25, S37, S96

French, R., 1213, S111

French-Monar, R. D., S37

Friedt, W., 1391
Friesen, T. L., 592, S3, S66

Fromentin, J., 611

Fruit, organic, Pennsylvania, transition, S44

Fruit and nut crops, fungal diseases, California, S170

Fry, W. E., S16, S146

Fu, D., S54

Fuentes-Davila, G., S37

Fuentes-Ramírez, L. E., S70

Fujisawa, M., 598

Fukuda, H., S108

Fukui, R., S79

Fukuoka, S., 598

Fulbright, D. W., S95

Fuller-Schaefer, C., S160, S162

Fumigant (see also Soil fumigant)

-methyl bromide: alternative chemical, S40, $\mathrm{S} 50$; ornamental crops in Florida and California, S101; use in Florida, S88

Fungicides (general) (see also Fungicides, specific)

- cotton damping-off, with biocontrol, 66

—Karnal bunt of wheat, foliar applications, S37

-Pantoea ananatis on onion, copper sensitivity, 1298

-Phytophthora root rot of blueberry, Mississippi, S183

-resistance identification, method, S27

- systematic spraying strategies, rules and financial benefits, 1484

Fungicides (specific) (see also Fungicides, general)

-Benlate, Leatherleaf fern, distortion syndrome, S182

- carbendazim, Fusarium graminearum resistance, China, 1584

- carboxylic acid amide, Phytophthora infestans on potato and tomato, 1274

- copper, sweet cherry cankers, management, S18

-flumorph, Phytophthora melonis, 643

-Mandipropamid, late blight and downy mildew control, S161, S170

- propiconazole, Monilinia fructicola resistance, instability, 448

-QoI: cucumber and eggplant fungal pathogens, 1458; sensitivity to Mycosphaerella fijiensis on banana, 1451

Funk, C. R., S8, S177

Funnell, D. L., S37

Furuta, A., 1458

Fusarium spp.: on cotton, molecular identification, S63; fungicide sensitivity, Red River Valley, S15; on lupine, yield effect, S20; on maize, seedborne, S100; on maize, seed disease transmission, S132; on maize ears, resistance, mycotoxins, 311; soybean, multiple gene genealogies, $\mathrm{S} 40$; on Spartina alterniflora, survey, S32; on sugarbeet, yellows, S160; on wheat, crop residue effect, 971; on wheat, no-till cropping system, PCR, S47

-F. culmorum: on barley, hormone role, S29; on wheat, seedling resistance, $\mathrm{S} 92$

$-F$. equiseti, on gingeng: host range and mycotoxin, S42; seed transmission, S95

-F. graminearum: on barley, blight and mycotoxin, 1054; barley-rice cropping system, Korea, S86; on bean, genotype reaction, S10; cell surface organization, pathogenicity role, S164; on corn and soybean, Ohio, S159; genotypes producing trichothecene, S15; germling development, peptide inhibition, S43; insertional mutants, reproduction, S128; mycotoxins, fungicides and cultivars, S162; and population genetics, hosts, S15; population subdivision sensu stricto, midwestern U.S.A., 1434; on potato, sugarbeet, and wheat, pathogenicity, S160; vegetative compatibility, carbendazim resistance, China, 1584; virulence, cell surface organization, S99; on wheat, blight and deoxynivalenol, S39; on wheat, blight resistance, trait locus, 592; on wheat, deoxynivalenol and nivalenol chemotypes, S48; on wheat, management and modeling epidemics, $\mathrm{S} 85$; on wheat, other isolates and mycotoxins, 835; on wheat, potato and sugarbeet comparison, S160; on wheat, tebuconazole and deoxynivalenol, 211

-F. oxysporum: on Acacia koa, Hawaii, S127; on birdsfoot trefoil, vegetative compatibility, S125; on chickpea, races 0 and 5, wilt factors, 564; on cotton, imported from Australia, S65; on Dianthus caryphyllus, race 2, defense model, S173; on flax, pathogenicity, S164; on ginseng, root effect, S95; on Hibiscus sabdariffa, S93; on lettuce, phylogeny, 87; on lettuce, race 1 , diagnosis, 987; on lettuce, seed dispersal, S72; population characterization, race and vegetative compatibility, 461; on tomato, yeast for biocontrol, S32 -F. solani: on potato, proteinase interaction, S112; on soybean, root, molecular quantification, S39

-F. verticillioides: on corn, ear infection, S127; fumonisin gene cluster, banana, S41; on maize, fumonisins in India, S102; media for conidia and fumonisin production, S63

-F. virguliforme, on soybean: inoculum and timing, S41; spread in Minnesota, S69

Fusicladosporium carpophilum, on nectarine and peach, fruit age and inoculum concentration, S179

Fussler, L., S38

Gabriel, D. W., S30, S85, S97

Gadoury, D. M., 512, 979, 1356, S5, S38, S39, S80, S119, S141

Gagnevin, L., 1568

Galbraith, D. W., S121

Gale, L. R., 1434, S48

Gallegos, L. L., S38

Gallian, J. J., S111

Galloway, H., 1290

Gallup, C. A., S38, S42

Galvani, C. D., S26

Gamliel, A., 1476, S44

Gandía, M., 1004

Ganesan, U., S38

Gao, X., S39

Garber, N. P., S39

Garibaldi, A., 987, S95

Garrett, K. A., S36, S102, S110

Garrison, M. C., S38

Garza, A. A., S39

Garzon, C. D., S39

Gasic, K., S185

Gastrodia elata, Anti-Fungal Proteins from, root rot and root-knot affected by, S82

Gatineau, F., 72

Gaudet, D. A., 1397

Gautam, P., S39

Geary, B., S19, S23, S32, S57

Geddens, R. M., S28

Gee, C. T., S39, S40

Geiser, D., S52, S93, S157

Genda, Y., 787

Gent, D., S40, S92, S167, S170

Geotrichum spp.

- G. candidum, on peach and nectarine, California, S126

-G. citri-aurantii, in citrus, DMI fungicides, S74

Geppert, R. L., S20

Ger, M.-J., 900

Gerbasio, A., S111

Gergon, E., S149

Gerik, J. S., S40, S101

Germplasm

-Cicer sp., breeding application, S151

- collections and modern technology, S151

- Global Crop Diversity Trust, resource conservation, S151

-National Plant Germplasm System, overview, S150 
-National Small Grains Collection, past and future, $\mathrm{S} 151$

Gevens, A. J., 421

Ghabrial, S. A., 79, 1255, S54

Ghoshroy, S., S169

Giammaria, S. L., S40

Gibberella spp.

- G. circinata, on pine, California, S168

-G. fujikuroi, phylogenetics, new species in complex, S52

$-G$. zeae: on wheat, inoculum density and weather factors, 1608; on wheat and maize, populations in Nepal, S51

Gibson, D. M., S112

Gieck, S. L., S167

Gilbert, C., S186

Gilbert, E., S111

Gilbert, R. L., S40

Gilbertson, R. L., S30, S124, S154

Giles, C. G., S81, S105

Gilkey, M., S135

Gillen, A. M., S171

Gillespie, M., S16

Gillett, J. M., S104

Gingery, R. E., S54

Giosuè, S., 352, 1422, 1625

Girke, T., S58

Gisi, U., 1274

Gisler, L., S61

Gitaitis, R., 1298, S84, S182

Glaeser, J., S41

Glais, L., S101, S153

Glasner, J. D., 1150, S71

Glass, B. W., S104

Glawe, D. A., 1290, S65

Gleason, M. L., S28, S30, S41, S46, S82, S91, S108, S113, S125, S147

Glen, M., 132

Glenn, A., S6, S41, S127

Glenn, D. L., S92

Global trade, plant health relation, S135

Globodera spp.

-G. pallida, protein elicits $\mathrm{R}$ gene, cell death, S103

- G. rostochiensis, on potato, molecular characterization, $\mathrm{S} 67$

-G. tabacum, on tobacco, resistance, S185

Gloer, J. B., S94

Glomerella cingulata, on cucurbits, biocontrol with Bacillus mycoides, S83

Glover, K., S61, S164

Gmitter, F. G., S56

Gnanamanickam, S., 373

Goates, B. J., S41, S151

Godoy, C., S33

Goh, E., S72

Goldberg, I., 384

Goldberg, N. P., S37, S96

Goldman, P. H., S98

Golod, J., S61

Gómez, G., S175

Gongora-Canul, C., S41

Gonsalves, D., S23, S144

González, A., S8, S173

Gonzalez, C. F., S139

Gonzalez, E. T., S58

González García, M., S174

Goodwin, P., S18

Gordon, S. G., 106, 113

Gordon, T. R., S99, S102, S168

Goss, E. M., S41

Gossen, B. D., S20, S42, S115

Goswami, R. S., S42, S95

Gotta, P., 1422

Gottwald, T. R., 674, S11, S30, S90

Gould, A. B., S178

Gourabathini, P., S141

Govers, F., S146

Goverse, A., S103
Gowda, M., S42

Gowda, S., S121

Goyeau, H., S89

Grabau, E. A., S184, S185

Grabherr, M., S146

Grabosky, J., S178

Graham, J. H., 958, S42, S142

Grant, S., S71

Grape

-ampeloviruses, leafroll-associated, S1

—apple pathogens in common, S38

— berry development, resistance, S40

- Botryosphaeria canker, California, S117

-Botrytis cinerea, Pythium elicitin, 611

—crown gall, biocontrol, S25

- decline, diatrypaceous fungi, ecology, California, S115

—disease resistance, DNA fragments, S20

- downy mildew: resistance and incompatibility, 780; sporangial survival, epidemiology, 512

— downy and powdery mildew, resistance, S16

-Eutypa dieback: climate effect on symptoms, 1284; PCR for detection, 737

-flavescence dorée, epidemiology in Italy, 1422

-National Grapevine Wood Disease Survey, France, S38

—ontogenic resistance, wild germplasm, S39

-Pierce's disease: endophytic bacteria, S123; New Mexico, S96; vectors in North Carolina, 1440

- powdery mildew: advisory system in cool climates, S80; fungicide program, S18; gene expressions, S119; insect feeding, cover photo, October; juice and wine quality affected by, 1356; resistance mechanisms, S16; spore detection in air samples, 1290; temperature and radiation effect, S5

—pruning wounds, esca, S33

- Pythium and Phytophthora spp., status in South Africa, S110

-ripe rot, epidemiology, S122

- sour rot and Botrytis, management, S101

-Togninia, California, S168

- viral diseases, new in California, S171

-weed management, effect on bacteria, S90

- Xylella fastidiosa, fimbrial and afimbrial adhesions, 318

Grapefruit, canker, streptomycin control in Brazil and Florida, copper, S42

Grapevine leafroll-associated virus-2, molecular variability, Washington, S51

Grau, C. R., 1519, S162, S163

Gravel, V., S178

Graw, R., S92

Gray, M. C., S42

Gray, S., S77, S153

Green, M., S157

Green, S., S22

Greene, M. D., S42

Greene, S. E., S44

Greenhouse gases, microbial populations, soil health, S106

Greer, C. A., S19

Gregoire, G., S42

Grenier, E., S103

Grewal, P., S89

Gries, C., S111

Griffin, T. S., S61

Griffiths, H. M., S43

Grimme, E., S43

Grisham, M. P., 748, S43

Grodzinsky, D. M., S163

Groenewald, J. Z., 825

Groenewald, M., 825

Grosman, J., S38

Gross, D., S16, S97, S156

Gross, N. W., S43

Groth, D., S82

Grove, G. G., 1290, S40, S92, S170
Grover, V., S43

Groves, R., S22, S108

Gruber, B. R., S43

Grünwald, N. J., 470, S41, S73, S168

Grybauskas, A. P., S185

Gu, G., S67

Gu, H., 79, 1255

Guaragna, M., S54

Gubler, D., S111

Gubler, W. D., S33, S36, S38, S92, S93, S101,

S111, S115, S117, S168

Gubrij, K., S52

Gudmestad, N. C., 1331, S124, S159, S160, S164

Gudmestad, N. G., S153

Guerra, A. S., S174

Guest, D., 1650, 1654

Guevara, G., S112

Gugino, B. K., S141

Gullino, M. L., 987, S44, S95

Gulya, T. J., S11, S164

Guo, B., S68

Guo, Q., S138

Gurr, G. M., S40

Gutierrez, D. L., S103

Gutierrez, W., S76

Gutierrez-Chapin, L., 756

Gutsche, O. W., S28

Guzmán, M., 1112, S175

Gwinn, K. D., S44

Hackett, W. P., S14

Hadas, Y., 384

Hadizadeh, I., S8

Hafidi, M., 338

Hagan, A. K., S17, S44

Hagen, C., S154

Hagiwara, K., 712

Haigler, C., S49

Hajeri, S., S44, S155

Hajimorad, M. R., S31, S129

Halbert, S., S70, S70, S96

Halbrendt, N. O., S44

Halgren, A., 37

Hall, B. D., S65

Hall, S., S146

Hallen, H. E., S51

Halseth, D. E., S43

Hamada, H., 787

Hamelin, R. C., 603, 632, 1177, S10, S35

Hamilton, G., S178

Hamilton, J., S14, S61

Hamm, P. B., S167

Hammer, W., S49

Hammerschmidt, R., S48, S134

Hammond, J., S45, S117, S131, S144

Hammond, R. B., S78

Hammond, R. W., S45, S121

Han, S., S21, S100

Handoo, Z. A., S152

Handsaker, R., S146

Hanna, J. W., S138

Hanna, L. T., S102

Hansen, E. M., 684, 1558

Hansen, M. A., S185

Hanson, P., 930

Hanson, S. F., S37, S96

Hao, G., S25

Harakava, R., S70

Hardin, Y., S87

Harikrishnan, R., S161

Harmon, C., S28, S88

Harmon, P., S13, S28, S54

Harp, T., S45, S170

Harper, S. J., S45

Harpin, V., S94

Harrington, T. C., 1648

Harris, R., S45

Harris, S., S99, S164

Harrison, L. A., S168 
Harrison, N., S100

Harte, B., S3

Hartman, G. L., 366, S29, S39, S76, S110

Hartung, J. S., 1338, S116

Harveson, R. M., S45, S46, S161

Hasama, W., 1458

Haslem, P., S25

Hassell, R., S182

Hatvani, L., 532

Hau, B., 1231

Hausbeck, M. K., 421, S95

Hay, F. S., S53, S92

Hayashi, Y., S108

Hayden, H. L., 879

Haynes, K. G., S123

Hayslett, M., S46

Hazard, N., S90

He, S., S115

Heaney, S. P., 1451

Hebbar, P. K., 1658

Heerema, R. J., S37

Heidenreich, C., S38

Helminthosporium solani, mycoparasitism by Acremonium strictum, 1331

Hemnani, K., S46

Henick-Kling, T., 1356

Herbicide, glyphosate, Mn immobilized, disease effect, S168

Hermann, D., S161

Hermansen, A., 979

Hernandez-Martinez, R., 857, S46

Hernández-Zepeda, C., S46

Herrero, M. L., S38

Hershman, D. E., 211, S61, S90, S140

Hert, A. P., S46, S71

Heterobasidion annosum, on Christmas tree, Pacific Northwest plantations, 551

Heterodera spp., interspecific isolates, molecular markers, host-range phenotype, S23

-H. avenae, on cereal, phosphite inhibition, 396

-H. glycines: resistance genes, S66; on soybean, resistance and reproduction, $\mathrm{S} 40$; on soybean, root response and CLE peptides, S98; on soybean, tillage system effects, S106

Hibbing, M. E., 1150

Hibiscus latent Fort Pierce virus, on maple, association, S3

Hickman, L., S84, S181

Higashi, T., 712

High Plains virus, on sweet corn, Washington and Oregon, S167

Higuera, B., S174, S175

Hilf, M. E., S121

Hill, J. (Canada), 1071

Hill. J. H. (Iowa), S31, S129

Hill, J. P. (Colo.), S11

Hillman, B., S8, S16, S25, S177, S178

Hinton, D. M., S6, S87

Ho, H. H., S47

Ho, J., S149

Hoagland, R. E., S13, S121

Hobbs, H. A., 366, S29

Hoch, H. C., S26

Hodda, M., S157

Hodges, A., S47, S88

Hoenisch, R. W., S47, S166

Hoff, T., S185

Hofstadler, S., S94

Höfte, M., 373

Hogenhout, S. A., S54

Hogetsu, T., 304

Hogg, A. C., S47

Hoheisel, G., S170

Hoitink, H. A. J., 429

Holb, I. J., 1104, S47

Holbrook, C. C., S25, S181

Holen, D. L., S80

Holland, J. B., 311

Hollingsworth, C. R., S5, S80, S161
Hollosy, S. I., S48

Hollowell, J. E., S134

Holmes, G., S2, S24, S31

Holovachov, O., S132

Holshouser, D. L., S185

Holterman, M., S132, S133

Honda, K., 712

Honeycutt, C., S61

Honeycutt, W., S87

Hong, C. X., S47

Hong, S., S48, S62

Hong, S. G., 87

Hong, S. S., S48

Hong, Y. Y., S48

Honjo, H., S79

Hoogenboom, G., S87

Hooper, G. R., S57

Hopkins, A., S128

Hopkins, D., S67

Horevaj, P., S48

Horn, B. W., S79, S96

Horowitz Brown, S., S48

Horseradish, fungal pathogens, thermo-therapy for eradication, S33

Horsfall-Barrett scale, repeal, S137

Horvath, B. J., S113, S134

Host-parasite interaction, viral protein, nucleic acid effectors, S145

Hotchkiss, M., S67

Hotte, N., S107

Hou, A., S107

Hou, M., 1590

Hou, R. F., 287

Houot, V., 611

Howard, R. J., S20, S49

Howell, C. R., 66

Howlett, B. J., 879

Hoy, J. W., S43

Hoy, M. W., S23, S74, S181

Hs, P., S48

$\mathrm{Hu}, \mathrm{C} ., \mathrm{S} 99$

Hu, G., 1063

$\mathrm{Hu}, \mathrm{H} ., \mathrm{S} 106$

Hu, J., S68, S106, S108, S112

$\mathrm{Hu}, \mathrm{S} ., \mathrm{S} 142$

Hu, X., S153, S155

Hua, L., S120

Huang, G., S126, S144, S156

Huang, H.-C., 1590

Huang, H.-E., 900

Huang, Q., S60, S61

Huang, Y., S49

Huber, D. M., S168

Hudler, G. W., S83

Hudson, L., S49

Huerta-Espino, J., S136

Huettel, R., S87, S112

Hughes, G., S147

Hughes, J., S3, S86

Hughes, L., S146

Hughes, T. J., 1519, S162

Hulbert, S. H., 1083, S36, S106, S150

Hunt, E. N., S103

Huryn, K., S26, S30

Hussey, R., S126, S144, S156

Husson, C., 99

Hwang, J., S49, S119

Hwang, S., S20, S49

Hyaloperonospora parasitica

—on Arabidopsis, signaling network, resistance, S185

—effector proteins, conserved, S184

—pathogenicity effectors, S146

Hydrangea, powdery mildew, resistance, S64

Hyman, B. C., S133

Hypersensitivity, Xanthomonas oryzae and Burkholderia andropogonis, defense signaling, S106

Hyun, J., S53
Idris, A. M., S14, S46, S49, S174

Ignacio Cardenas, S., S102

Ignatov, A., 803

Igo, M. M., S71, S72

Impatiens flower break virus, new virus, New Guinea, S54

Impullitti, A. E., S162

Inderbitzin, P., S49

Information system dissemination, S140

Ingham, R. E., S167

Inoue-Nagata, A. K., 702

Integrated pest management (see also Management and Pest Management)

-bacterial wilt of tomato, potato, and ornamentals, strategy, S148

- Melaleuca quinquenervia, Florida invasive, S149

-nematodes, global perspective, S148

-reporting methods, S156

-Tobacco etch virus, Jamaica, S148

—vegetable cropping system, Asia, S149

International shipment, horticulture industry, regulations, S136

Internet, information delivery, farmers, S15

IR-4 project, registration, S13

Iriarte, F., S50, S141

Iriki, N., S84

Iris yellow spot virus

- emergence in western U.S.A., S167

-new weed hosts, S103

-NSs protein, antibodies, S89

- on onion, leaf distribution, S182

Irrigation, beans and bacterial wilt, severity in

Nebraska, S45

Irvine, J., S51

Isakeit, T., 311

Isard, S., S30, S33, S139, S140

Ishida, G. I., S50

Ishihara, H., S106

Ishii, H., 1458

Islam, M. A., 1406

Isleib, T. G., S134

Isogai, M., 1200

Ito, M., S84

Ivors, K., S38, S42, S98, S157

Izzo, A. D., 454, S50

Jablonski, R., S109

Jackson, A. O., S38

Jackson, C., S124

Jackson, E. W., 1063

Jacobi, V., S4

Jacobi, W. R., S59

Jacobsen, B., S43, S50, S83

Jacob-Wilk, D., S50

Jacquot, E., S27, S101, S153

Jahn, C. E., S50

Jaime-Garcia, R., S51, S88, S168, S169

Jamai, A., S66, S126

James, A. D., 504

James, R. L., S51, S127, S168

Jan, F. J., 287, S22, S125

Janisiewicz, W. J., S51

Janousek, C. N., S101

Jansky, S. H., 865, S4

Jaraba-Navas, J., S51

Jaronski, S. T., S160, S162

Jarosz, A. M., S51

Jarugula, S., S51

Jeffers, S. N., S49, S74, S119

Jeger, M. J., 1550

Jelesko, J., S186

Jenkins, D., S51, S60

Jenks, M. A., S39, S40

Jensen, S., S32

Jensen-Tracy, S., S109

Jeon, N., S110

Jeong, K., S52

Jepson, P., S92

Jeuffroy, M., S91 
Ji, P., S52

Jia, M. H., S52

Jia, Y., S25, S52, S120

Jian, D., 1590

Jiang, R., S146, S184

Jiménez, J. I., S75

Jiménez-Díaz, R. M., 564, 1380

Jimenez-Gasco, M. M., S52

Jin, Y., S136, S137, S162

Jo, Y. (Mass.), S52, S53, S58

Jo, Y.-K. (Ohio), 170

Jobin, T., S177

Johnson, B. J., S1

Johnson, C. S., S185

Johnson, D. A., S168

Johnson, J., S145

Johnson, K. B., 1263, S169, S171

Johnson, R. M., 748

Johnson, S. B., S178

Johnson, W. A., S53

Johnston, M. R., S83

Johnston, R. H., S47, S53

Jolivet, J., S123

Joly, D. L., S35, S53

Jomantiene, R., S53

Jones, D., S105, S124

Jones, J., S7, S8, S37, S46, S52, S56, S71, S121, S141

Jones, S. J., S92, S53

Jones, T., S80

Jonson, G. B., S53

Jordan, R., S54, S131

Jordan, S. A., 737

Joshi, R., 756

Jost, P. H., S181, S183

Jouen, E., 1568

Jovi, J., S54

Juba, J., S93

Judelson, H. S., S146

Juglans spp., crown gall, resistance, S58

Jung, G., 767, S52, S53, S58

Jung, K., S160

Jurick, W. M., II, S54

Juzwik, J., S10, S46

Kachroo, A., S54

Kachroo, P., S54

Kaiser, W. J., 1600, S79

Kajamuhan, A., S55

Kaku, E., S154

Kale, S., S55, S146

Kaloshian, I., S70, S143

Kaminski, J. E., S21

Kamoun, S., 429, S39, S146

Kanda, A., 412, 787

Kanematsu, S., 278

Kang, L., S119

Kang, S., S84, S157

Kanobe, C., S100

Karakkat, B. B., S55

Karasev, A., S61, S144

Karchesy, J. J., 850

Karsavuran, Y., S103

Kassemeyer, H.-H., 780

Kastelein, K., 971

Katagiri, S., 598

Katan, J., 1476

Kato, M., S33

Katoh, H., 557

Kaur, R., S55

Kav, N., S107, S126

Kawada, N., 1054

Kazmierczak, P., S50

Keane, P., 1654

Kega, V., S121

Keinath, A. P., S55

Keith, R. C., S84

Kelemu, S., S16, S55

Keller, N. P., S48, S55
Kelly, A. G., S128

Kelly, J. D., S149

Kelman, A., 1150

Kelsey, R. G., 850

Kema, G. H. J., 1112

Kemerait, R. C., Jr., S87, S181, S183

Kemp, J. D., S96

Kempf, H.-J., S161

Kenji, F., S108

Kennedy, G. G., 1440, S79

Kennelly, M. M., 512, S74

Kerlan, C., S101, S153

Kern, J., S56

Kerns, J. P., S56

Kerry, B., S157

Kessel, G., S109

Khalaf, A. A., S56

Khan, A., S56

Khan, I. A., S2

Khan, M., S13, S15, S29, S56, S160

Khan, Z., S57

Khandekar, S., S57

Khangua, R., 1011

Khodjhaeva, A. K., S106

Khot, S. D., S10

Killgore, E., S105

Killiny, N., S57

Kim, B., S86

Kim, H., S57, S108, S110

Kim, H. G., S82

Kim, H.-S., 1150, S127

Kim, J., S35, S53, S57, S108

Kim, M., S53, S138

Kim, S., S84

Kim, W., S48, S62

Kim, Y., S57, S62, S108

Kimura, I., 712

Kinkel, L., S153

Kirk, W. W., S7, S122

Kirkpatrick, B. C., S17, S76, S118, S123

Kirkpatrick, T. L., S51, S150

Kiseleva, M. I., S57, S60

Kistler, C., S48

Kistler, H. C., 1434

Kitz, L., S57

Klassen, W., S88, S107

Kleijnen, J. P. C., 945

Klein, E., 1476

Kleinhenz, B., 1186

Klich, M., S88

Kline, W. L., S125

Klink, V., S72

Klittich, C. J., S58

Kloepper, J. W., S180, S181, S182

Klopfenstein, N. B., S138

Klopmeyer, M., S131, S136

Klossner, L. D., S112

Klosterman, S. J., S58

Kluepfel, D. A., S34, S58, S73, S90

Knogge, W., 650

Knoth, C., S58

Ko, T. S., 366

Kobayashi, D. Y., 233, S141

Kobes, N., S38

Koch, C., S142

Koch, P. L., S58

Koch, S., 1186

Koczan, J. M., S59

Kodira, C. D., S146

Koenning, S. R., S150

Koenraadt, H., S59

Köhl, J., 971

Kohn, L. M., 470, S134

Koike, S. T., S166

Koizumi, S., 598

Kokalis-Burelle, N., S101, S180

Kokko, E., S115

Kolmer, J. A., 344, 574, 1141, S87

Kolomiets, T. M., S59, S60
Kon, T., S154

Koopmann, B., 1391

Korban, S. S., 366, S185

Koropacka, K., S103

Koski, R. D., S59

Koski, T., S11

Kosma, D., S39, S40

Kosman, E., 1231

Kosta, K. L., S92

Kousik, C. K., S2

Kousik, C. S., S59, S60, S182

Kousik, S., S99

Kovalenko, E. D., S57, S60

Kowitwanich, K., 113

Kox, L. F. F., 1119

Kraft, J., S77

Krasnoff, S. B., S112

Kraus, J., S60, S77

Kredics, L., 532

Krewer, G., S20

Krnjaji, S., S54

Kubicek, C. P., 532

Kubota, A., 412

Kubota, R., S60

Kuhn, D. N., 1664

Kuhn, P., S45, S170

Kuldau, G. A., 504, S52, S123, S148

Kumar, S., 592

Kunkalikar, S., S97

Kunkel, D. L., S13

Kunta, M., S60

Kuo, C.-G., 900

Kurle, J. E., S76, S112

Kutin, R., S60

Kuznetsov, A. M., S106

Kuznetsova, T. V., S106

Kwanyuen, P., S117

LaBonte, D., S23, S74, S76

Lachenbruch, B., 1558

Lacorte, C., 702

Lagenaria siceraria, powdery mildew, tolerance, S60

Laird, D., S45

Lakshman, D., S61

Lakso, A. N., S5

Lalancette, N., S15, S177, S179

Lalli, D. A., S185

Lambert, K. N., 366

LaMondia, J. A., S179

Lamour, K. H., 421, S78, S146

Landa, B. B., 564, 1380

Lang, G., S48

Lang, J., S14, S61

Lange, H. W., S12

Langham, M., S61

Langrell, S. R. H., 132

Langston, D., Jr., 1298, S182

Languasco, L., 359

Lanier, W., S15, S59

Lannou, C., S89

Lardner, R., 1284

Larkin, R., S61, S87

Laroche, A., 1397

Larsen, B., S50

Larsen, H. J., S93

Larsen, J. E., S5

Larsen, R. (New Zealand), S62

Larsen, R. C. (Wash.), 1290, 1519

Larson, B., S162

Larson, R. L., 1245

Lartey, R. T., S169

Lashomb, J., S178

Lasso, M. J., S62

Latin, R., S73

Lawrence, C., S78

Lawrence, K., S44, S180

Lawrence, N. P., S86

Lazarovits, G., 1071 
Leach, J, S14, S18, S36, S61, S106

Leandro, L., S41

Lebas, B. S., S45, S86

Leconte, M., S6, S72

Ledbetter, C., S22

Lee, B., S48, S52

Lee, M.-H., 269

Lee, M.-J., 900

Lee, R., S68, S70, S96, S174

Lee, S. (Canada), 1177

Lee, S. (Korea), S48, S52

Lee, S. (Pa.), S62

Lee, S. (U.K.), S146

Lee, S. H. (N.D.), 155, 162, 538, 938

Lee, Y. (Seoul, Korea), S157

Lee, Y. (Suwon, Korea), S62

Lee, Y.-A. (China), 195

Lefebvre, A., S18

Legard, D. E., 1130, S75

Leggett, F., 1397

Lego, S. F., S75

Legume, disease management, PIPE as tool, S61

Lehman, B. L., S44, S83

Lehman, J. S., 1022

Lehmensiek, A., S12

Leisner, S., S57, S62

Leite, B., S63

Leite, R. P., S42

Lema, M., S30

Lemos, E. G. M., 1543

Lenssen, A. W., S169

Lenzi, R., S98

Leonard, G., S13

Leonard, K. J., 484

Leptosphaeria maculans

—on canola: ascospore discharge, Australia, 1011; resistance proteins, S107; systemic acquired resistance, 794

- genetics, microsatellite and minisatellite analysis, Australia, 879

Leslie, C. A., S14

Lesniak, K. E., S63

Letter to the editor, fire blight prediction, Billing's integrated system, 1036

Lettuce

- downy mildew, sporulation factors, 979

-Fusarium wilt: Arizona, S169; phylogeny of fungus, 87 ; race 1 , diagnosis, 987

- Sclerotinia disease, sclerotial germination and forecasting, 621

- Sclerotinia rot, biocontrol with Coniothyrium minitans, Korea, S62

- Sclerotinia sclerotiorum, California populations, 470

—Verticillium wilt, colonization, S117

Lettuce infectious yellows virus

—encoded proteins, analysis, S155

-inoculation systems, S119

Leung, H., S18, S100

Levchuk, T. P., S106

Leveillula taurica, on sweet pepper, microclimate effect, 813

Lévesque, A., S14

Lévesque, C. A., 632, S10, S100

Levi, A., S60

Levy, L., S64, S66, S82, S129, S147

Lewandowski, D. J., S131

Lewellen, R. T., S65

Lewis, E., S143

Lewis, K. J., 825

Lewis, L., S94

Lewis Ivey, M. L., 429, 1467, S9, S63

Lherminier, J., 611

$\mathrm{Li}, \mathrm{C} ., \mathrm{S} 86$

Li, F., S94

Li, G. Q., 1590

Li, H., S27

Li, J. Q., 643, S35

Li, R., S64, S117
Li, S., S64, S110

Li, W., 1338, S64

Li, X., S144

Li, Y., 643, S64

Liao, H., S64

Liles, M., S182

Lily, fungal pathogens, microarray assay for detection, S21

Lim, H. S., 366

Lin, F., S21, S120, S169

Lin, H., S29, S64, S127

Lin, M. (Ark.), S52

Lin, M.-K. (China), 900

Lin, S.-S., 287

Lind, V., 523

Linde, C. C., S128

Lindow, S. E., 318, S120, S141

Ling, K., S60, S65

Ling, P., S171

Lipps, P. E., 211, 1608, S90, S159

LiPuma, J. J., S139

Lithocarpus densiflorus, sudden oak death, stem water relation, 1558

Little, C. R., S39, S102

Liu, B., 1305, S66

Liu, C.-A., 900

Liu, G., S52

Liu, H. (Ga.), S66

Liu, H.-Y. (Calif.), 1245, S65

Liu, J. (Texas), S65

Liu, J. (Md.), S68

Liu, J.-J. (Canada), 728

Liu, P. F., 643

Liu, Q., S65

Liu, S., S66

Liu, X. (Mo.), S66

Liu, X. L. (China), 643

Liu, Y., S65, S66, S125, S145

Livingston, S., S67

Llamas, M. J., 1049

Lo, C., S67

Lockhart, B., S3, S67, S118, S131

Loeb, G., S141

Lolium spp., crown rust, resistance, mapping, 767

Lolium latent virus, molecular characterization and taxonomy, S117

Loper, J. E., 233

Lopera, C., S5

Lopes, J. S., S3

López, D., S175

Lopez, G., S104

López, M. O., S175

Lorenzen, J. H., S153

Loria, H., S102

Louws, F. J., S99

Louzada, E., S60

Loveday, R., S184

Lozoya-Gloria, E., 51

Lu, J., S29

Lu, S., S67

Lu, X., S68, S160

Lu, Z.-X., 1397

Lucas, J. A., S9

Lühs, W., 1391

Lui, Z., S64

Luo, C., S68

Luo, M., S68

Luo, Y., S68

Lupien, S. L., S167

Luster, D., S4, S9, S68, S137

Luz, E. D. M. N., 492

Luzón, O., S173

Lycoperdon perlatum, on creeping bentgrass, fairy ring, S77

Lynch, S. C., 1366, S36

Ma, B., 1150, S69

Ma, H., S68

Ma, J., S120
Macarisin, D., 1491, S69

Maccree, M. M., S58

MacDonald, J. D., S126

Mace, E., S12

MacGuidwin, A., S158

Machado, M. A., 1543

Macias, F. A., S6

MacKenzie, S. J., 1130, S69, S79

Macrophomina phaseolina

—on snap bean, seed treatment and cultural practices, S181

-on soybean, propagule densities, Mississippi, S75

Madden, L. V., 211, 429, 1608, S78, S85, S90, S97, S147, S163

Madeiras, A. M., S78

Madoui, M. A., S162

Magarey, P. A., 512

Magarey, R., S140

Magnaporthe spp.

-M. grisea: avirulence gene, molecular mechanisms, S25; infection structure development, cyclic AMP, S86; on rice, defense-related genes, resistance, 170; on rice, Gene Oncology database, S75; on rice, partial resistance gene, mapping, 598; on rice, RNA species, S42; on rice, transcription factors, $\mathrm{S} 10$

$-M$. oryzae: on rice, effectors, biotrophic invasion, S145; on rice, model pathosystem, genetic dissection, S120; on ryegrass and kikuuyugrass turf, cross-infectivity, S56

Mahaffee, W. F., 1290, S92, S169, S170

Mahoney, N. E., S89

Mahovic, M., S8, S69

Mahuku, G., S69

Mailhot, D., S63

Maiorino, G., S98

Maize (see also Corn)

—aflatoxin analysis, defense-related genes, S68

-aflatoxin in kernels, endosperm proteins, 1094

-aflatoxin-producing fungi, Mexico, S88

—anthracnose, fiber cell colonization, 438

_Diplodia ear and stalk rot, PCR assay, S35

- downy mildew resistance screening, S173

-Fusarium and Aspergillus ear rots, resistance and mycotoxin, 311

—inbred, aflatoxin-resistance markers, S14

-northern leaf blight, variation in races 1,23 , and $23 \mathrm{~N}$ in U.S.A., 1501

-redness, Reptalus panzeri and phytoplasma role, Serbia, S54

—sphinganine, mycotoxins in silage, 504

-Stewart's wilt and leaf blight, detection methods, S35

Maize chlorotic mottle virus, Wheat streak mosaic virus, double infections, on maize, synergism, 1213

Maize dwarf mosaic virus, yield losses, Colombia, S173

Makalowska, I., S157

Makowski, D., S69

Malnoy, M., S185

Malvárez, G., 470

Malvastrum leaf curl Guangdong virus, monopartite begomovirus, $\mathrm{S} 130$

Malvick, D. K., S69, S162

Mamillapalli, P., S145

Management (see also Integrated Pest Management and Pest Management)

—apple brown rot, 1104

-nematodes, ecology, S143

-Plant Management Network, electronic resource, S156

Manczinger, L., 532

Mandrell, R. E., S138

Mangifera indica, bacterial black spot, pathovar distinctions, 1568

Mangravita-Novo, A., S85

Manjunath, K. L., S70, S96, S174 
Mansfield, M. A., 504, S148

Mansour, M. F., S78

Mantelin, S., S70

Manter, D. K., 850

Manuscript preparation, author's guide, 7

Mao I. Hoeschele, Y., S160

Maragos, C. M., 311

Marçais, B., 99

Marcon, A., S28

Marek, L. F., S11

Marek, S. M., S16, S28, S182

Marin, D., S6

Marin-Cevada, V., S70

Marine, S. C., S70, S185

Marois, J., S30, S33, S54, S63, S83

Maroof, S. A., S160

Maroon-Lango, C. J., S117

Marquez-Villavicencio, M., S71

Marr, S. K., S38

Marra, R. E., S179

Marshall, D. S., S33

Martin, D. P., 702

Martin, F. N., 492, 632, S71, S117, S157

Martin, J., S156

Martin, R. R., 37, S60, S71, S116

Martínez, F., 1578

Martínez, G., S173

Martínez, J. L., S174, S175

Martínez, S., S173, S175

Martins, M. C., S33

Marutani, M., S46, S71

Marzachì, C., 1422

Marzano, S. L., S71

Mascarúa-Esparza, M. A., S70

Masenga, V., S98

Masiri, J., S81

Matheron, M. E., S71, S169

Mathew, F. M., S162

Mathews, D. M., S131

Matsumoto, A., S71, S72

Matsumoto, T., 598

Matta, A., S69

Matthews, B. F., S72

Maughan, P. J., S23

Maule, A. J., S132

Maumy, M., S38

Mavrodieva, V., S66, S147

Maxson-Stein, K. L., S162

Maxwell, N., S125, S179

May, G., S118

Mayorga, R., S175

Mazzani, C., S173

Mazzola, M., 454, 1348, S50, S72, S110, S114, S142

Mbofung, G. C., S72

Mbofung, G. Y., 87

Mboup, M., S72

McCall, D. S., S113

McCarter, J. P., S156

McClean, A. E., S73

McCloskey, A. K., S169

McClung, A., S52

McCollum, T. G., S2

McCoppin, N. K., 366

McDonald, B. A., S128

McDonald, M., S73, S115, S169

McDonald, S. A., S148

McDonald, V. T., S73

McDowell, J., S184, S185, S186

McDuffee, D. A., S73

McFarland, K. A., S179

McGovern, B., S88

McGovern, R. J., S47

McGranahan, G. H., S14

McGrath, M., S2, S59, S73, S74, S178, S179

McGregor, C., S23, S74

McKay, A. H., S74

McKellar, M., S47

McKenna, F., S32
McKenney, D., S179

McKenry, M., S157

McKeown, A., S115

McLane, H. L., S112

McLaughlin, I. M., S74

McLeod, A., S110, S114

McMahon, M. B., S68

McManus, P., S30, S43, S93

McMullen, M. P., 211, S15, S90, S162

McNamara, B., S12

McNeal, D., S151

McRoberts, N., S147

McSorley, B., S101

McSpadden Gardener, B. B., 221, 756, 1467, S9, S89

Meacham, T., S153

Medicago truncatula

-plant-microbe interaction, defense response, S103

—powdery mildew, resistance mechanisms, 1049

Medina, V., S155

Meekes, E., S74

Meinhardt, S., S3

Meister, C., S52, S121

Meitz, J., S146

Meksem, K., S66

Melampsora spp., on poplar: avirulence genes, S53; effector identification, S35

-M. medusae, on poplar, genetic diversity, sympatry and allopatry, 603

Melcher, U., S43, S75, S81

Melhus Graduate Student Symposium, S154

Melidossia, H., S141

Melinger, C., S50

Meliola sp., on Brosimum gaudchaudii, Brazil, S91

Mello, A., S74, S75, S127, S172

Meloche, C., S177

Meloidogyne spp.: cell-wall synthesis, analysis, $\mathrm{S} 49$; perineal patterns, phase microscopy, S31

-M. incognita: on corn, race $3, M$. arenaria race 1 comparison, S44; parasitism genes, analysis, S126; plant-host compatibility effectors, S9

$-M$. javanica, on pineapple, cystatin effect, S108

- M. marylandi, on cereal, phosphite inhibition, 396

-M. spartinae, on salt marsh grass, characteristics, S179

Melotto, M., S115

Melton, R., S94

Méndez-Rodríguez, M. A., 564

Meng, F., S75

Meng, S., S75

Mengistu, A., S75

Menkir, A., S14

Menz, M., 1063

Mera, J. R., S9

Mercado-Blanco, J., S7

Mercier, J., S41, S75, S78

Merremia leaf curl virus, Sweet potato leaf curl virus comparison, on weeds, New World, S14

Merremia mosaic virus, clones in Puerto Rico, S174

Merrifield, K. E., S167

Mertely, J., S75, S88

Mertensia paniculata, tymovirus, new, S100

Meshi, T., 412

Messika, Y., 813

Metarhizium anisopliae

— control by bacteria, S162

-on plant roots, S160

Meyer, M. M., S76

Meyer, P. W., S76

Miano, D., S23, S74, S76

Michailides, T. J., S5, S68, S87, S126, S169, S170

Michereff, S. J., S137

Microdochium nivale, on wheat, crop residue effect, 971

Microsphaeropsis sp., on pyrethrum, new disease, S92
Mideros, M., S160

Mideros, S., 655, S163

Mihail, J., S94

Mila, A., S76, S79, S140

Milat, M.-L., 611

Milde, L., S55

Miles, M. R., S76

Milgroom, M. G., 584

Miller, E. S., S29

Miller, G., S34, S77

Miller, J., S50

Miller, M. L., S60, S77

Miller, S.(Canada), S152

Miller, S. A. (Ohio), 429, 1467, S9, S63, S149

Miller, W., S77

Miller-Butler, M., S182

Milling, A., S28, S77

Mills, H. A., S181

Milus, E., S48

Min, J., S57, S108

Minton, B., S170

Misra, M. K., S35

Mitchell, A., S40

Mitchell, T., S16, S42, S75, S78, S86

Mitchum, M. G., S66, S98

Mitkowski, N. A., S78

Mitreva, M., S156

Mitrovi, M., S54

Mittal, S., S128

Miyara, I., 1415

Mlikota Gabler, F., S78

Mmbaga, M. T., S64, S78, S80, S85

Mock, R., S64

Model

-Bayesian statistics, S147

- Cercospora leaf spot on sugar beet, epidemiology, 1550

- disease dissemination, California system, S140

-disease forecasting, economic, S147

-disease progress curve, analysis, 1231

- disease risk prediction, economic validation, S114

—disease warning system, weather, S147

-fire blight blossom forecast, MARYBLYT and Cougarblight, comparison, 1164

-Fusarium head blight, wheat, risk assessment, S147

-long distance transport, aircraft, S147

- metamodel, Ralstonia solanacearum on potato, 945

—operational deployment, success and failure, S140

—output interpretation, S140

-random pattern, theoretical variance, law of probability distribution, S179

-rust simulation, weather, S92

- Sclerotinia sclerotiorum on lettuce, sclerotial germination, 621

-Sclerotinia stem rot in Brassica napus, forecasting, 1186

-stochastic, spore dispersal and deposition rates, 1325

-synthetic RPP8 gene clusters, unequal crossingover, S186

—validation concepts, S147

-Western Weather Systems Workgroup, IPM, S92

-wheat stripe rust, anisotrophic dispersal, 1315

Moffett, P., S103

Mohamed, N., 611

Mohammadi, M., S98

Mohammed, C. L., 132

Mohan, K., S103

Mohan, S. K., S167

Molendijk, L. P. G., S152

Molineros, J. E., S78, S147, S163

Molnar, T. J., 311, S8, S177

Moml, T. M., S71

Momol, M., S7, S98, S141

Momol, T., S46, S47, S52, S88, S121

Mondal, S. N., S79 
Monfort, W. S., S150

Monilinia spp.

-M. fructicola: benzimidazole-resistant isolates, S68; fungicide sensitivity, S68; fungicide sensitivity assay, 1376; on peach, propiconazole resistance, 448; on peach, QoI fungicides, S15; propiconazole resistance, $\mathrm{S} 25$; propiconazole sensitivity, S47; on Prunus spp., exocarp phenols, 269

-M. fructigena, on apple, management and dropped fruit, 1104

Montarry, J., 338

Monteiro, J. E., S125

Montero-Astúa, M., 1338

Montes-Borrego, M., 1380

Montesinos-Herrero, C., S89

Moore, G. A., S35, S56

Moore, G. G., S79, S96

Moore, P., S108

Moorman, G., S62

Mor, M., 396

Moral, J., S79

Morales, N. P., S8

Morales-Payan, J. P., S107

Moreira Ascarrunz, S. D., S79

Morel, W., S76

Morelock, T. E., 1305

Moreno-Valenzuela, O. A., S46

Morgan, D. P., S68, S170

Morgan, W., S146

Morliere, S., S27

Morone, C., 1422

Morris, T. J., 1213, S111

Morsello, S., S79

Mosjidis, J., S81

Mostowfizadeh-Ghalamfarsa, R., S79, S80

Motamayor, J. C., 1664

Motteberg, C. D., S5, S80, S161

Mourits, M., 945

Moyer, M. M., S80

Mozzoni, L. A., S101

Mpofu, S. I., S164

Mrema, F. A., S78, S80, S85

Msikita, W., S80

Muchero, W., S80

Muchovej, R. M., S99

Mudgett, M. B., S145

Muehlbauer, F., S151

Muehlbauer, G. J., S149

Muehlchen, A., S142

Mueller, D. S., S41, S125, S159

Mukhina, Z. M., S59

Muli, H., S121

Mullin, P., S133

Mullinix, B., 1298

Mullis, L., S181

Mullis, S., S84, S182

Mulrooney, R. P., S185

Mumma, E., S81

Munck, I., S81

Munkvold, G. P., S132

Muñoz-Ledesma, F. J., 1380

Muñoz-Rojas, J., S70

Munyaneza, J. E., S166

Murphy, C. J., S43

Murphy, J. F., S81

Murray, S., S62

Murray, T. D., S84, S168

Murraya paniculata, host for Huanglongbing, S26

Muscodor albus

- biofumigant for disease, S75

-fumigation, ozone compared, postharvest gray mold, S78

Mutegi, C. K., S81

Muthukumar, V., S81

Mwange, K. N., S113

Mwangi, M., S63

Mycena citricolor, on coffee, epidemic in Costa Rica, 1532
Mycoparasitism, Helminthosporium solani by Acremonium strictum, 1331

Mycorrhizae, arbuscular mycorrhizal fungi, plant health link, S142

Mycosphaerella spp.: on banana, molecular diagnostics, 1112; on Eucalyptus, PCR detection, 132

-M. fijiensis, on banana: diversity in Hawaii, S126; QoI sensitivity, Costa Rica, 1451; virulence assay, 916

-M. graminicola: azole sensitivity, molecular mechanisms, S24; fungicide sensitivity, sterols, S9; on wheat, fungicide resistant alleles, S36

Mycotoxin

—aflatoxin, maize endosperm proteins, resistance relation, 1094

—barley, infection timing, 1054

-deoxynivalenol and tebuconazole, Fusarium blight of wheat, 211

- detection technology, S148

-Fusarium graminearum on wheat, potato, and sugar beet isolates, 835

—regulation, challenges, S148

-silage, detection and quantification, S148

-sphinganine, maize silage, factors, 504

Myers, A. L., 440

Myers, K., S16

Myndus spp., lethal yellowing vector, genetic marker, $\mathrm{S} 174$

Myre, W., S100, S176

Myrothecium verrucaria

-bioherbicide, trichothecene gene formulation, S121

-mycoherbicide for kudzu and sesbania, method, S13

Mysore, K. S., S119, S120

Naeve, S., S112

Nagabhyru, P., S6

Nagai, C., S108

Nagel, A. K., S82

Nagy, E., 532

Naidu, R. A., S3, S51, S97

Nakajima, T., 1054

Nakamura, H., 278

Nakhla, M. K., S82

Nam, M. H., S82, S91

Nandakumar, R., S82

Napier, B., 297

Narvaez, D., S33, S54, S63, S83

Nascimento, F. E., S3

Natarajan, S., S61

National Plant Diagnostic Network

-agricultural biosecurity, S166

-education, S47

National Plant Germplasm and Biotechnology Laboratory, validating methods, S147

Natsuaki, T., 1200, S79

Navas-Cortés, J. A., 564

Navia, M., S69

Neate, S. M., 155, 162, 538, 938, S15, S112

Neelam, B. A., S4

Negi, S. S., S129

Neher, O., S50, S83

Nelson, A. H., S83

Nelson, B., S94, S163

Nelson, G. A., S112

Nelson, M., S40, S170

Nelson, R., S15, S19, S56, S83, S151, S160

Nematodes

- attractant orientation, S143

-biology from 1750 to $2008, \mathrm{~S} 158$

- Brassica crop effects, nematicides, S155

- contribution to plant pathology, S158

-cotton: management, S150; nematicides, S150; reniform nematode, $\mathrm{S} 150$

- cotton root-knot, molecular markers and mapping, S150

-culture methods, S133

- cyst, parasitism and effectors, S145
-Dorylaimia: cladistics and classification, S133; molecular phylogeny, S133

- endoparasitic, crystal proteins, S144

- genomics and data navigating, internet, S156

- Longidoridae and Trochodoridae, virus transmission, S133

-management: disease complexes, S155; organic amendments, S156

-Mermithida, mitochondrial genomics and phylogeny, S133, S134

-Mononchida, systematics, S133

—nematicide development, twentieth century, S157

-NemATol database, S157

—parasitism genes, engineering resistance, S156

- on pea, Washington and Oregon, S167

-plant pathology and entomology bridge, S158

-resistance, biotech crops, S144

-resistance genes, transfer, S143

-revolution in 300 years, S157

-root-knot, parasitism genes, S144

-roots and shoots, multigene datasets, S132

—-soil ecosystem, key species, S157

—-species keys, using INTKEY, S157

- Tree of Life project, phylogeny, S133

-Triplonchida, phylogeny, S132

Neosartorya fischeri, vegetative compatibility, S166

Nephotettix cincticeps, Rice dwarf virus vector, virus retention, 712

Nesmith, S., S13

Nester, S. E., 997

Nettleton, D., S84, S117

$\mathrm{Ng}, \mathrm{C} . \mathrm{K} ., \mathrm{S} 33$

$\mathrm{Ng}, \mathrm{J} ., \mathrm{S} 44$

Ngugi, H. K., S81, S83

Nguyen, H., S114

Ni, H., S21

Niblack, T., S23, S39

Nicotiana spp. (see also Tobacco)

$-N$. benthamiana: gene silencing, virus induced, squalene synthase, S119; movement defective viruses, recombination, S19

-N. glutinosa, tombusvirus resistance gene, S7

Niem, J., 1415

Nierman, W. C., S166

Nightengale, S. P., S17, S44

Nikolaeva, E. V., S84

Nimbya spp., biocontrol agent, alligatorweed in Australia, S40

Nino-Liu, D. O., S84

Niranjana, S. R., S102

Nischwitz, C., 1298, S84, S182

Nishijima, K. A., S84

Nishijima, W. T., S84

Nishimura, K., 1458

Nishio, Z., S84

Nita, M., 655, S33, S85, S123

Nix, S. S., S85

Nix-Stohr, S., S182

Njau, P., S136

Njihia, S., S121

Nnodu, E. C., S80, S85

Noe, J. P., S6

Nordskog, B., 979

Norelli, J. L., S185

Norman, D., S52, S85

Norton, A. P., S141

Norton, G., S149

Noussourou, M., S154

Novy, R. G., S153

Nowak, R., S17

Nusbaum, C., S146

Nutter, F. W., Jr., S68, S85, S110, S137, S147, S160

Nyczepir, A. P., S82

Oak

-bacterial leaf scorch, New Jersey, S178

-wilt: beetles in Texas, S46; root grafts, S10

Oak, S. W., S49 
Oat, crown rust, resistance genes, assessment methods, 1063

Oben, T. T., S86

Oberle, C. S., S123

Obert, D. E., 1063

Obradovic, A., S141

O'Brien, G., S83

Ocamb, C. M., S170

Ochoa Corona, F. M., S45, S86

Ochoa-Martínez, D. L., S108

O'Donnell, K., S157, S178

Oerke, E.-C., 1222

Oertel, B., S46, S113

Ogbe, F. O., S3

O'Gorman, D., S142

Oh, E., 684, 1558

Oh, I., S86, S100

Oh, S.-K., S146

Oh, Y., S86

Ohki, T., 412

Ohkura, M., S86

Ohnishi, J., 787

Ohtani, K., 557

Oikawa, Y., 278

Ojiambo, P. S., S148

Oka, Y., 396

O'Keeffe, T. L., S89

Okubara, P. A., S86, S105, S170

Olano, C. T., 1664

Olanya, M., S87

Olanya, O., S61

Olatinwo, R. O., S87

Olaya, G., S2, S87

Oliva, R., S39

Olivaras-Fuster, O., S87

Oliveira, R., S79

Oliver, B., 803

Olivieri, F., S112

Olsen, M. W., S96, S170

Olson, S., S52, S98, S121

Olson, T. N., S84

Olubajo, B., S87

Omura, T., 712

O’Neill, N. R., 1305

Ong, K., S110

Onion, center rot, fatty acid methyl profiles, copper sensitivity, 1298

Onoue, M., 278

Oomycetes

—DNA barcoding, S100

- effectors, structure and function, S146

Opgenorth, D., S167

Ophiosphaerella spp.

-O. herpotricha: on bermudagrass, fluorescent protein, S16; on native grasses, root colonization, S119

-O. korrae: on bermudagrass, management strategies, S91; on Kentucky bluegrass, fertilizer and fungicide effects, S13

Ophiostoma spp.

-O. clavigerum, Dendroctonus ponderosae association, genetic diversity in British Columbia, 1177

-O. novo-ulmi, on elm, bark beetle vector, Colorado, $\mathrm{S} 59$

-O. piceae, wood staining, pigmentation genes, 1040

Opina, N., 1467, S149

Oral, B., S10

Ordoñez, M. E., 344, 574, 1141, S87

Orlandini, D. R. S., 702

Ornamentals, leaf scorch, phylogeny of strains, 857

Oropeza, C., S100, S176

Ortega-Beltran, A., S88

Ortiz-Ribbing, L. M., S88

Oryza spp., blast, resistant gene variation, S120

Osborne, A., 756

Osborne, L., 1608, S163, S164
Osekre, E., S63

Osorio, J., S16

Østergård, H., 1325

Otrosina, W. J., S88

Otsyula, R., S69

Oude Lansink, A., 945

Oudemans, P. V., S93

Owens, K. J., S82, S129

Ownley, B. H., S44

Ozdemir, N., S103

Ozone, snap bean response, New York, S179

Pacheco, M. P., 1083

Palencia, E. R., S88

Pallas, V., 892

Palm, M. E., S185

Palmateer, A. J., S88, S93

Palmer, G. K., S183

Palou, L., S89

Palumbo, J. D., S89

Pan, Q., S120

Pandelova, I., 694

Pantoea spp.

- $P$. agglomerans, on maize, wilt and leaf spot, Mexico, S108

- P. ananatis, on onion, fatty acid methyl profiles, copper tolerance, 1298

-P. stewartii: on corn, probes for detection, S35; detection with PCR assay, S113

Papastamati, K., 202

Papaver somniferum, downy mildew, phylogenetic analysis, PCR detection method, 1380

Papaya ringspot virus, on tomato, Mexico, S174

Pappu, H., S89, S101, S103, S167

Paret, M. L., S89

Pariaud, B., S89

Park, B., S157

Park, J., S53, S157

Park, K., S62

Park, M. S., S90

Park, S., S48, S84, S89, S90, S157

Parke, J. L., 1558, S36

Parker, P. E., S11

Parker, S. R., S90

Parkunan, V., S185

Parnell, S. R., S90

Parrott, L. A., S128

Parrott, W., S156

Partridge, D. E., S184, S185

Parveen, G., S31

Pasche, J. S., S124, S159, S160, S164

Pasquali, M., 987

Pastalka, T., S101

Pasura, A., S90

Pathogens

—detection using PRI probes and PCR, S12

-forest, invasive, sources, S138

-invasive: disjunct plants, S138; phylogenetic analyses, S138

Pathosystems, fungal, new tools, S182

Patiño, L. F., S175

Patterson, G., 1071

Paul, P. A., 211, 1608, S14, S85, S90, S163

Paulitz, T. C., S105, S170

Paull, R., S108

Paulsen, I. T., 233

Pavek, M., S89

Pavon, C., S6

Payan, L., S45, S170

Payne, G. A., 311, S29, S56, S109

Paz, J. O., S87

Pea

-Clover yellow vein virus, resistance, 544

-root rot, rolling and phosphorous acid effect, S94

—white mold, resistance sources, S170

Pea enation mosaic virus, seed borne, S62

Peach

_brown rot lesion, fungicides, S177 -leaf curl: seasonal dynamics in orchards, 352; spore production and budding factors, 359; weather effects, 1625

Peanut

— aflatoxin contamination, Kenya, S81

-bacteria and crop rotation, S112

- early leaf spot, strip tillage effect, 187

- Rhizoctonia diseases, resistance in Texas, S183

-Sclerotinia blight: fungicides, S25; pathosystem, S134; resistance genetically modified, S185; resistance and SSR marker, S22

- seed-borne fungi, detection, S32

- seed treatment, diseases and yield, S180

- transgenic, oxalate oxidase, resistance government approval, S184

Pear

-fire blight, pathogen survival on fruit, 1263

— gray mold, model for cold storage, S110

-Phacidiopycnis rot, timing in orchard and storage, S65

Pearson, M. N., S12, S45

Peas, lentil comparison, Sclerotinia sclerotiorum, Washington, 470

Pectobacterium spp.: genomic comparisons, S71; host range and molecular phylogenies, 1150

Pedersen, J. F., S37

Pedley, K. F., S4

Peetz, A., S170

Peever, T. L., 551, S65, S79

Peiman, M., S23, S91

Pellé, R., 338

Peltier, A. J., S163

Pelzer, E., S91, S92

Peng, G., S42

Penicillium spp.

- $P$. digitatum, on citrus: hydrogen peroxide burst, S69; hydrogen peroxide suppression in hosts, 1491

-P. expansum, on apple: gluconic acid and glucose oxidase, 384; postharvest decay in Kazakhstan, S51

Penman, L. N., S21

Pentastiridius sp., sugar beet, proteobacteria syndrome, 72

Peñuela, S., S103

Pepino mosaic virus, on tomato, greenhouses in North America, S65

Pepper golden mosaic virus

-on Capsicum annuum, resistance and symptom remission, 51

-tolerance phenotype, non-coding sequence, S49

Pepper mild mottle virus

- on Capsicum spp., coat protein and amino acid, 787

-RNA silencing, replication protein, 412

Pereira-Carvalho, R. C., S91

Perera, O. P., S1

Peres, N. A., 1130, S69, S75, S88, S106

Perez, C. A., S91

Pérez, Y., S175

Pérez-Hernández, O., S28, S82, S91

Perkovska, G. Y., S163

Perna, N. T., 1150, S71

Pernezny, K., S109

Peronospora spp.

- P. arborescens, on opium poppy, phylogenetic analysis, PCR detection, 1380

-P. farinosa, on quinoa, electron microscopy, S57

-P. tabacina, on tobacco, population analysis, $\mathrm{S} 11$

Peronosporales, mitochondrial genomic, phylogenetics and molecular markers, S71

Perry, C. D., S9

Perry, H., S91, S114

Perry, K. L., 119, S2, S113, S153

Perry, R., S143

Perugini, L., S150

Pesticides, stone fruit replant problem, Colorado, S93

Pest information, platforms, architecture, S139 
Pest management (see also Integrated Pest Management and Management)

- systematic spraying strategies, crop protection rules, 1484

Peterson, G. L., S92

Pethybridge, S. J., S53, S92

Petitt, F., S49

Petri, C., S82

Petrisko, J. E., S92, S124

Peyrard, N., S92

Pfender, W., S92

Phaeosphaeria nodorum, on wheat, seed transmission, 584

Phakopsora pachyrhizi

- on kudzu, survival in Florida, S54

-on soybean: defense peptide, S34; factors in Brazil, S33; protein profile, S90; resistance gene, S117; spore germination factors, 997; spread in southeastern U.S.A., 1428; temperature effect on urediniospore, $\mathrm{S} 81$

-spore biology, clumping, S63

- spore dispersal, long distance in rain, S8

- spore wall proteins, S68

-urediniospore germination, light effect, S159

Phaseolus lunatus, downy mildew, development monitoring in field, $\mathrm{S} 185$

Phellinus sulphurascens, on Douglas-fir, hostpathogen interactions, 1406

Phelps, K., 621

Phialophora gregata

- genotypes A and B, molecular quantification, S162

—on legumes, PCR evaluation, S162

Philion, V., S93

Phillips, D. V., S183

Phillips, M., S152

Phillips-Mora, W., 1644, 1664

Phipps, P. M., S184, S185

Phoma spp.

-P. ligulicola: on pyrethrum, host range in Tasmania, S92; on pyrethrum and chrysanthemum, phylogeny, S53

-P. lingam, on brassica, seed treatment, S167

- P. medicaginis, on alfalfa, model pathosystem, S28

- P. sclerotioides, on wheat, Minnesota, S161

Phomopsis longicola, on soybean, oil for seed decay, S64

Phragmidium violaceum, factors in Pacific Northwest, S169

Phyllocnistis citrella, citrus, canker relation, Brazil, 674

Phylloplane, tall fescue, yeast population, wounding effect, S85

Phyllosphere

-Lysobacter-Magnaporthe interaction, model, S141

—mites and powdery mildew, grape, $\mathrm{S} 141$

_phages, S141

- protozoa and enteric pathogens, S141

Phylogeny, Phytophthora cryptogea and $P$ drechsleri, multiple gene genealogy, S80

Phylogeography, trophic, research program, S143

Phytoalexin, bacterial lipases, bacteriostatic, S97

Phytophthora spp.: on citrus, hypovirulent isolate competition, 958; database, online, S157; detection, COXI-COXII spacer region, S117; on Fraser fir, microbiological profiling, S98; gene phylogeny, S91; irrigation water, San Joaquin Valley, S104; on ornamentals, California, S126; ribosomal nucleotides for identification, S79; on trees, Tennessee, S78

-P. alni, on alder, decline factor, France, 99

-P. cactorum, on strawberry: fungicides, S97; PCR for detection, $\mathrm{S} 10$

- $P$. capsici: asexual reproduction, soil extracts, 873; on bell pepper, skin separation, S125; on chile pepper, Verticillium dahliae interaction, 37; crown and fruit rots, irrigation water, 421; diversity, temperate and tropical isolates, 492; on Fraser fir, susceptibility, S95; genome sequence, S146; haplotypes of, Florida, S37; oospore survival, soil, S6; on pear, use as bait, cover photo, April; on pepper, resistance, S17; on tomato, salinity-induced predisposition, S29; on watermelon, GPS technology, S9; on watermelon, resistance, $\mathrm{S} 182$

- P. cinnamomi: on blueberry, phosphonates for, $\mathrm{S} 13$; on blueberry, resistance screening technique, S182; in forest soil, survival, burning, S74

-P. citricola: on black walnut, stem canker, S159; on walnut, resistance, $\mathrm{S} 14$

-P. erythroseptica: fungicide efficacy, S160; on potato, $\mathrm{pH}$ effect, $\mathrm{S} 10$

-P. infestans: on bean, sanitizer treatments, S116; developmental stages, carboxylic acid amide fungicides, 1274; effector protein, species complex, S39; genome, analysis, S146; on hairy nightshade, alternate host implication, S87; mating type A2, in Colombia, S118; molecular phylogeny, S23; oomycete effectors, S145; on potato, partial resistance, adaptation, 338; on potato, U.K. archives, S99; spore development transcriptional network, S146; viruses in, S16

- P. inundata, on alfalfa, California, S47

-P. lateralis, Port-Orford-cedar, resistance, histopathology, 684

- $P$. melonis, microfilament organization, flumorph effect, 643

-P. nicotianae: races, North Carolina, S38, S76; on tobacco, population biology, S42

- P. palmivora, pod rot, cover photo, December

- P. pseudosyringae, forest streams, North Carolina, S49

$-P$. ramorum: avirulence gene family, $\mathrm{S} 41$; biology and effect, S168; detection methods, 1119; diagnostics, real-time PCR, 632; National Survey and Compliance Testing, S129; PCR diagnostics, federal surveys, S129; photosynthesis and water stress, elicitins, 850; polymorphisms, codon volatility, S10; in red oak, redwood, and tanoak forests, survival in California, S36; rhododendron, infection and sporulation, S73; risk in Canada, S179; sporulation survival, California redwood-tanoak forest soil, 1366; suburban waterways, South Carolina, S119; survey in New York and Northeast nursery, S109; on tanoak xylem, stem water transport effect, 1558

-P. siskiyouensis, on alder, California, S101

-P. sojae: effector repertoire, $\mathrm{S} 146$; on soybean, PCR assay, transposable element, S110; on soybean, resistance, 106; on soybean, resistance, components, 655, S163; on soybean, resistance, plant introductions 113

Phytoplasma

- aster yellows, cereals, Minnesota, S5

- symptom expression genes, S121

-on wheat, cultivar response, S161

Phytotoxin

- fumonisin and aflatoxin, in maize ears, 311

-Rhizoctonia solani, rice susceptibility and sensitivity, 1207

Pickup, J., S152

Picton, D. D., S129

Piedrahita, R. A., S175

Pierce, M. L., S43, S81

Pierson, E. A., 227

Pierson, L. S., III, 227

Pieterse, C. M. J., 239

Pilcher, C., S156

Pilet, F., 338

Pin, H., S86

Pine

- longleaf and slash, wildfire and Ophiostomatoid spp., S88

—rust, ecology and phylogeography, S138
Pineapple

-badnavirus-like sequences, Hawaii, S106

-mealybug wilt-associated viruses, badnaviruses, Hawaii, S112

—pink disease, Enterobacteria, S70

Pines, O., 384

Pinus spp.: Dothistroma needle blight, mating type genes, 825 ; pine wilt disease, genetic structure of populations, 304

- P. monticola, blister rust, resistance and genes, 728

$-P$ radiata, pitch canker and shoot blight, resistance, S99

Pinzón, A., S8

Pipatpongpinyo, W., 113

Piriformospora indica, on wheat, biocontrol agent, 523

Pitman, T. L., S93

Plantanus racemosa, anthracnose, microinjection therapy, S114

Plantegenest, M., 1484

Plant growth-promoting rhizobacteria, fertilizer and environment effects, S180

Plant health

—nematode indicators, S142

-soil, bacteria, fungi, and nematodes, S154

- soil indicators, roots, S142

Plasmopara viticola, on grape:

- host-pathogen interaction, incompatibility, 780

-QoI sensitivity, North Carolina, S69

—resistance, cover photo, July

-sporangial survival, epidemiology, 512

Platt, D. H., S93

Platz, G., S12

Platzer, E. G., S134

Pleurotus spp., green mold, Trichoderma spp. cause, 532

Ploetz, R. C., 1634, S93

Plum bark necrosis stem pitting associated virus, detection and analysis, S4

Plum pox virus

- microelectronic chip technology for detection, S66

—new, New York, S109

Poa trivialis, dollar spot, silicon effect on, S34

Podosphaera spp.

-P. macularis: on hop, Pacific Northwest, S170; on strawberry, overwintering in New York and Norway, S38

-P. xanthii: on pumpkin, biopesticides, S178; on squash and pumpkin, management, S73

Poinar, G. O., Jr., S134

Pokharel, R. R., S93

Polashock, J. J., S93

Poling, S. M., S94

Poojari, S., S97

Popescu, V., S124

Populus deltoides, leaf rust, genetic diversity, sympatry and allopatry, 603

Porchas, M., S71, S169

Poromarto, S., S94, S163

Porter, L. D., S94, S167, S170

Posos, P., S175

Posos-Ponce, P., S174

Postharvest pathology

- acetaldehyde, release in spoiled fruit, S3

-apple core rot, seed locule colonization, 1415

- apple and pear diseases, new in Pacific Northwest, S171

-Penicillium digitatum on citrus fruit, hydrogen peroxide role, 1491

Postnikova, E., S94

Potato

-black dot and pink rot, cultivar screening, S43

-breeding and certification in North America, S153

-cyst nematode: decision support system, S152; Idaho, S151; molecular identification, national survey, S82; Quebec, Canada, S152; regulation, 
Europe, S152; sampling method, S152; status in U.S.A., S151

- early dying, volatile compounds of Muscodor albus, S43

- Globodera pallida, characterization in Idaho, S152

-late blight: BLIGHTSPACE model, Netherlands, S109; management with wet-based system, Michigan, S122; partial resistance, 338; PCR-based markers, S123; synoptic forecast, S7 -pale cyst nematode, identification in U.S.A., S152 - phosphytes, tuber application, S62

- pink rot and leak, resistance and fungicides, S164

- purple top phytoplasma, beet leafhoppers, detection, S166

-Ralstonia solanacearum, cost-effective control options, 945

—scab, geocaulosphere, factors, 1071

- seed-borne diseases, fungicide treatment, S122

- seed production, methods, worldwide, S153

- soilborne diseases, management strategies, S61

— storage rots, phosphorous acid materials, S178

- tuber decay, storage, S5

-Verticillium wilt, PCR for detection, 865

Potato spindle tuber viroid

-detection, simultaneous macroarray, S2

-on tomato, protein kinase, S45

Potato virus $S$, molecular characterization in Washington State, S89

Potato virus $Y$

— crop changes, vectors, S153

- evolution, S153

-necrotic ability, S10

- sequence and recombination analysis, S155

- strains and variants, S153

Potebniamyces pyri, on pear, population structure in Pacific Northwest, S65

Potlakayala, S. D., 794

Potyviridae, cucurbits, vine decline, whitefly transmission, 145

Powell, J. F., S134

Powers, T., S14

Pradel, W., S102

Prakash, H. S., 1526

Prats, E., 60, 1049, 1578

Pratt, R. C., S54

Pratylenchus spp.

-P. neglectus: PCR for identification, S167; on wheat, depth distribution, $P$. thornei comparison, S170; on wheat, Montana, S53

$-P$. scribneri, on tall fescue, ergovaline toxicity, S6

Press, C. M., S41

Pretorius, Z. A., S137

Priest, M. J., S40

Probst, C., S94

Proctor, R. H., S41

Pruett, G., S94

Prunus spp.

-brown rot, exocarp phenols, 269

- pathogen detection, S105

Prunus necrotic ringspot virus, on apricot, pollen grain affected by, 892

Prusky, D., 384, 1415

Pruvost, O., 1568

Pryor, B. M., 87, S22, S72, S90

Pseudocercospora cornicola, on flowering dogwood, S24

Pseudocercosporella sp., on apple, species delineation, S113

Pseudomonas spp.: biocontrol, diversity and ecology, symposium, 221; biocontrol, integrated, symposium, 244; biocontrol agent, 30-year survey, symposium, 250; fluorescent, systemic resistance induced, symposium, 239; in rhizosphere, biocontrol, 756

-P. fluorescens: on Arabidopsis thaliana, systemic resistance, S7; biocontrol of Pythium spp., cyclic lipopeptide, 1348; genomic sequence, biocontrol, symposium, 233; Pythium suppressed by, lipopeptide surfactant, $\mathrm{S} 72$

- P. sevastanoi, on myrtle, histogenesis, S102

-P. synxantha, biocontrol agent, broad-spectrum activity, S34

-P. syringae: on Arabidopsis thaliana, water potential modulation, S36; on canola, systemic acquired resistance, 794; on crucifers, inoculum sources, S98; epiphyte, programmed cell death, S141; nonribosomal peptide synthetase system, S16; on sweet cherry, pruning and copper spray effect, S177; on tomato, chlorosis gene, S120; on tomato, choline uptake, S20; on tomato and pepper, PCR for identification, S104; Type VI secretion system, S97

Pseudoperonospora spp.

-P. cubensis, on cucurbit, fungicides, S24

-P. humuli, metalaxyl insensitivity, S40

Pseudotsuga menziesii, Phellinus sulphurascens on, seedling infection, 1406

Public health

- foodborne outbreak, detection, S139

-fresh produce, bacteria, S139

Puccinia spp.: on Alibertia sessilis, Brazil, S91; on cereals and grasses, detection using PCR, 717; on grass, Sphaerellopsis filum, hyperparasite, S55

-P. acroptili, pyncial crosses, U.S.A., Russia, and Turkey, S184

- $P$. andropogonis, on tallgrass prairie, drought and phytohormone relation, S36

- P. coronata: on oat, genes assessment methods, 1063; on oat, multiline variety, $\mathrm{S} 18$; on ryegrass, resistance, mapping, 767

- $P$. graminis: evolution and adaptation, S136; genome sequencing project, S113; on wheat, race TTKS, S162; on wheat, race Ug99, adultplant resistance, S136; on wheat, resistance genes, S137

- $P$. helianthi, on sunflower, resistance-inducing compounds, 179

- P. hemerocallidis, on daylily, hydrogen dioxide effect, S181

- P. hordei, on barley, metabolism inhibition, 1578

- P. jaceae, on yellow starthistle, biocontrol, $\mathrm{S} 124$

-P. melanocephala, on sugarcane, severity and soil property relation, Louisiana, 748

-P. striiformis: on barley, recessive gene, molecular mapping, 668; on barley, resistance, mapping, S171; epidemic growth rate, weather patterns, 1512; gene-specific PCR primers, use in taxonomy, S171; on wheat, epidemic growth rate and weather, 202; on wheat, genetic recombination, S72; on wheat, molecular markers for resistance, $\mathrm{S} 21$; on wheat, plot dispersal, modeling, 1315; on wheat and barley, races in U.S.A. in 2006, S21; on wheat, virulence cost, S6

-P. triticina: on durum wheat, world collection, diversity, 574; urediniospore germination, light effect, S159; on wheat, aggressiveness components, S89; on wheat, Asia and Caucasus, 1141; on wheat, durum phenotypes, worldwide collection, 344; on wheat, latent period heritability, 1022; on wheat, variation in North America, S87

Puchalski, B., 1397

Pugliese, M., S95

Pumpkin, Watermelon mosaic virus on, inter-row cover crops, S81

Punelli, M., S109

Punica granatum, gray mold, postharvest, S89

Punja, Z. K., S42, S95

Pusey, P. L., 1263, S95, S171

Putnam, M. L., S60, S77

Pye, M. F., S29

Pyrenophora spp.

-P. teres: avirulence gene, mapping, S66; on barley, avirulence gene, molecular markers, 842; on barley, proteinaceous metabolites, 907
- $P$. tritici-repentis, on wheat: races, phenotypes and genotypes, 694; races 1 and 2, S3

Pyricularia grisea, on turfgrass, mating types in California, S26

Pythium spp.: on bean, PCR markers, S69; control by Pseudomonas fluorescens, cyclic lipopeptide requirement, 1348; on corn and soybean seed, Ohio, S159; inter- and intraspecific characterization, S62; PCR and SSCP assays, S14; population in orchard soil, seed meal effect, S72; root dysfunction, North Carolina, S56

- $P$. aphanidermatum, temporal and spatial distribution, Pennsylvania, S62

-P. ultimum: in potting mixes, molecular detection, S90; on tomato, control in greenhouse, S178

$-P$. volutum, on creeping bentgrass, temperature, S56

Pytoplasma, genome plasticity, sequence variable mosaics, S53

Qandah, I. S., S95, S164

Qin, G. Z., 260

Qu, F., 1213, S111

Qu, R., S29

Qu, X., S123

Quarantine, international plant pathogen movement, S136

Quesada-Ocampo, L. M., S95

Quiñones, R., S176

Raaijmakers, J. M., 1348, S72

Radi, S. A., S164

Radionenko, M., S96

Radopholus similis, on Anthurium andraeanum, compost factor, S50

Rafael, G., 1491, S69

Rahman, M., S95

Raid, R. N., S95

Raja, P., S154

Rajaguru, A. P., S96

Rajakaruna, P., S3, S57

Rajotte, E. G., S149

Ralstonia sp., biopesticide for, clove oil, S61

$-R$. solanacearum: bacteriophage, detection, S60; detection with electrodes, S51; detection with LAMP, S60; on eggplant, diversity in Philippines, 1467; on geranium, international movement, S136; low temperature effect, pathogenicity variation, S85; mutation, virulence reduction, S75; on potato, metamodel, control options, 945; protein extraction method, $\mathrm{S} 61$; race 3 , gene identification, $\mathrm{S} 23$; race 3 , on potato, cold tolerance, S28; race 4, detection with indicator plants, S89; stress effects, culture conditions, S79; on tomato, defense genes, S77; on tomato, resistance enhancement by protein, 900; type II secretion system, S66; virulence and fitness, S127

Ramadugu, C., S70, S96

Ramírez, C., S182

Ramírez, R., S174

Ramirez-Prado, J. H., S79, S96

Ramos, C., S96

Ramos Ramos, E., S174

Randall, J. J., S37, S96

Randhawa, P., S104

Rapusas, H., S149

Rascoe, J. E., S97

Rasheed, M. S., 930

Rashid, K. Y., S164

Rasmussen, J., S3, S10

Raspberry, root pathogens, S104

Ratcliffe, S., S6

Rav, D. D. 813

Ravi, K. S., S97

Ray, J., S76

Ray, S. L., S58

Rayamajhi, M., S149

Raymundo, R., S102 
Read, A., S97

Rearick, E., S111

Rebollar-Alviter, A., S97

Records, A. R., S97

Red clover necrotic mosaic virus, cell-to-cell movement, S122

Reddy, J. D., S97

Reddy, K. N., S75

Redinbaugh, M. G., S54, S78

Reed, D. W., 794

Reed, S. M., S64

Reedy, R. M., 1150

Regulation

- free trade dilemma, Florida, S135

- free trade policy, perspective, S135

- planting and free trade, S135

- technical working group, potato cyst nematode role, $\mathrm{S} 151$

Rehmany, A., S146

Reid, C., S25

Reilly, C., S67

Reiner, W., S62

Reinholtz, C., S184

Reinsel, M. D., S45

Reis, R. N., S79

Reitz, S. R., S98

Remote sensing technology, GPS and GIS, pathogen detection, S137

Renteria, R., S98

Replogle, A., S98

Resistance

—Arabidopsis to disease, defense signaling, oleic acid, S54

_barley to disease, mapping, S149

-barley to Septoria speckled leaf blotch: resistance genes, 155; sequence tagged gene site markers, 162,538

-Brassica napus to Verticillium wilt, interspecific hybridization, 1391

- canola to Leptosphaeria maculans and Pseudomonas syringae, salicylic acid, 794

— corn to stalk rot, molecular breeding, S149

- disease progress and crop growth, factors, S178

-faba bean to rust, phenylpropanoid effect, 60

- jujube fruit to Penicillium expansum, glucanase genes, 260

-maize to Fusarium and Aspergillus ear rots, 311

-marker-assisted selection, experimental design, S149

- Medicago truncatula to powdery mildew, mechanisms, 1049

- oat to crown rust, assessment methods, 1063

- pea to Clover yellow vein virus, 544

- pepper to Pepper golden mosaic virus, 51

- Phaseolus vulgaris to disease, markers, S149

- potato to late blight, French and Moroccan populations, 338

- rice to blast, partial resistance gene, mapping, 598

-ryegrass to crown rust, mapping, 767

- soybean germplasm, change, S151

- soybean to: Phytophthora root and stem rot, 655; root and stem rot, genetic analysis, 106, 113

- turfgrass to Magnaporthe grisea, 170

-wheat to: bunt, Bt-10 gene, 1397; rust, microarray analysis, S150; rusts, gene patterns, 1083

—white pine to blister rust, 728

Restrepo, S., S5, S8, S118

Reuter-Carlson, U., S23

Reuveni, M., 1415

Reveche, M., S18

Reverberi, M., S109

Reviewers, acknowledgment, 4

Reyes, H., S68, S170

Rezaee, S., S98

Rezaian, M. A., 930

Rhizoctonia spp.: pathogen DNA from soil and plants, Pressure Cycling Technology, S86; on rice, genetics and pathogenicity in India, 373
- $R$. oryzae-sativae, on rice, diversity in California, S19

-R. solani: AG-3, quinic acid effect, S8; on bentgrass, resistance, $\mathrm{S} 177$; on radish, fungicides for, S9; on rice, PCR for detection, S104; on rice, phytotoxin sensitivity, susceptibility, 1207; on soybean, diagnosis, S162; vegetable diseases, New York, S86

$-R$. zeae, on Bermudagrass, Cuba, S174

Rhizopus stolonifer, fludioxonil sensitivity, S87

Rhizosphere

-bacteria, disease suppressive soil, S142

- soil health management, nematodes and soilborne diseases, $\mathrm{S} 141$

Rhodiola rosea, seedling and crown diseases, Canada, S49

Rhodococcus fascians

- on flowering potted plants, Pennsylvania, S84

- on herbaceous perennials, survival, S77

- phylogenetic analysis, S60

Rhynchosporium secalis

-on barley: asexual genetic exchange, 650; PCR detection, epidemics, 297

- host specialization, European origin, S128

Riault, G., S27

Ribeiro, S. G., 702

Rice

-bacterial pathogens, tissue-specific pathogenesis, S84

-blast: durable resistance, planting method, S100; oxalate oxidases, analysis, S18; partial resistance gene, mapping, 598; resistance genes in Colombia, S24

—blast and sheath blight, interaction, S52

-Cochliobolus miyabeanus, calcium effect on morphogenesis, 331

-disease resistance, genomics, S52

-Rhizoctonia sheath diseases, genetics and pathogenicity in India, 373

—seedling pathogens, environment effect, S31

— sheath blight, 1207

Rice dwarf virus, vectors, 6-year retention, 712

Richard, E. P., Jr., 748

Richard-Cervera, S., S123

Richardson, B. A., S138

Richardson, K. L., S21

Richlin, L., S155

Richter, B. S., S98

Ricker, M., S98

Rideout, S., S8, S185

Riegel, D. G., S5

Riga, E., S155

Riley, D. G., S97

Riley, R. T., S41

Riley, T., S90, S97, S105

Rinehart, T. A., S64

Rioux, D., S4, S179

Ristaino, J., S11, S99, S146

Ritchie, L., S98, S121

Ritokova, G., S99

Rittenour, W. R., S99, S164

Rivard, C. L., S99

Rivera, C., 1338

Rivera, V. V., 835, S160

Rivera-Bustamante, R. F., 51

Rivera-Varas, V. V., 1331, S15

Rizvi, A., S105

Rizzo, D. M., 1366, S29, S36

Robbins, R. T., S40, S133

Robert, C., S89

Robert, S. A., S51

Roberts, P. A., S80, S150

Roberts, P. D., 145, S2, S37, S59, S88, S99, S121, S182

Robertson, A., S68, S100, S110, S160

Robertson, C. L., S81, S178

Robertson, N. L., S100

Robertson-Hoyt, L. A., 311

Robideau, G. P., S100
Robinson, A. F., S150

Robinson, T., S18, S177

Roca, M. M., S100, S176

Rodrigues Neto, J., 1568

Rodriguez, C., S100

Roe, B. A., S81

Roegge, M. D., S88

Rogers, K. D., S94

Rogers, P. M., S100

Roh, J., S86, S100

Röhrig, M., 1186

Rojas, M., S154

Rojas-Molina, M. M., 60, 1578

Rolland, M., S101, S153

Rollins, J. A., S109

Rondeau, E., S42

Rooney-Latham, S., S33, S38, S101, S168

Roozbeh, M., S8

Rosales, M., S101

Rose, four new viruses, S67

Rose, L., S146

Rosellinia necatrix, mycoviruses, 278

Roskamp, G. K., S88

Rossi, V., 352, 359, 1422, 1625

Rossing, W., S109

Rosskopf, E., S50, S101, S107

Rossnagel, B. G., 842

Rosso, M. L., S101

Rotenberg, D., 756

Rothrock, C., S31, S51, S101

Rotylenchulus reniformis, on cotton, resistance, S34

Rouse, D. I., 865, S4

Rouse, M. N., S102

Rowhani, A., S1, S4, S171

Rubiales, D., 60, 1049, 1578

Rubino, M., S3

Rubio, L., 1004

Rubus occidentalis, Black raspberry necrosis virus, detection, 44

Ruden, B. E., S164

Ruden, K. R., S164

Rufina, H., S107

Rufty, T., S142

Ruhl, G., S47, S159

Ruiz, R., S102

Rumohra adiantiformis

— fern distortion syndrome, S181

-virus, S117

Rupe, J., S5, S40, S101

Rupestris stem pitting-associated virus, on grape, molecular diversity, S3

Rush, C. M., 325, S2, S124, S170

Rush, M. C., S82

Rygulla, W., 1391

Ryu, C., S119, S120

Saad, A. T., S102

Sabanadzovic, S., S1, S102, S103, S117

Sabbadin, R., S92

Saborío, F., S181

Sacco, M. A., S103

Sache, I., 1315

Saeed, M., 930

Sagehashi, Y., 1458

Saguaro cactus virus, capsid protein, molecular characterization, S122

Sahin, F., S103

Sainudiin, R., 584

Sakaue, D., 304

Salam, M. U., 1011, S91

Salas, B., S11

Salazar, L. F., S153

Salazar, L. M., S175

Salus, M., S58

Samac, D. A., S5, S103, S161

Sampangi, R., S103

Sampath, R., S94

Sanchez, A., 1315 
Sanchez-Pina, M. A., 892

Sandberg, E., S60

Sanders, H., 1298

Sanderson, R., S103

Sanogo, S., 37, 873, S103

Santamaria, L., S185

Santiago, R. P., S133

Santillán, J., S175

Santillán-Santana, J., S174

Santos, L. P., S91

Saponari, M., S104, S127

Sarpeleh, A., 907

Sasaki, A., 278

Sato, K., 787

Sato, M., 544

Sauve, R., S78

Savary, S., S38

Saygili, H., S103

Sayler, R. J., S104

Scapin, I., 1422

Schaad, N. W., 803, S35, S94, S104, S105, S106

Schafer, M., 470

Schardl, C. L., S6, S102

Schatz, B. G., S13

Scheffler, B., S114

Schein, J., S113

Scherm, H., 1104, 1376, 1428, S22, S47

Schiff, M., S145

Schiff, N. M., S123

Schilder, A. M. C., 737, S104

Schisler, D. A., S104

Schlub, R. L., S109

Schmale, D. G., III, S70, S147, S184, S185

Schmale, L., S136

Schmidt, F. J., S34

Schmidt, L. S., S14, S104

Schmitt, D., S157

Schnabel, G., 448, 1376, S25, S47, S68, S82

Schnable, P. S., S36

Schneider, B., 964

Schneider, D. J., S11

Schneider, J. H. M., 1550

Schneider, K. T., S117

Schneider, R. L., S178

Schneider, R. W., S19, S81, S105

Schneider, W. L., S26, S94, S105

Schnell, R. J., 1664

Schnurr, J., S103

Schoedel, B. A., S97, S105

Schoelz, J., S7, S34, S114

Schoen, C., S12

Schomaker, C. H., S152

Schoonveld, W., S73

Schroeder, B. K., S34

Schroeder, K. L., S86, S105

Schubert, T. S., S105

Schuenzel, E. L., 803, S104, S105, S106

Schulthess, F., S94

Schwartz, H., S61, S161, S167

Schweri, K. K., S102

Sclerospora graminicola, on pearl millet, management, glycoproteins, S107

Sclerotinia spp., oxalic acid and pathogenicity, S134

-S. homoeocarpa: on bermudagrass, biofungicides, S114; epidemiology, S134; taxonomic classification, clarification, S134; on turf, fungicides, S58; on turf, severity guide, S73; on turfgrass, fungicide and population shifts, S53; on turfgrass, management, S134; vegetative compatibility, nitrate mutants, S52

$-S$. minor, on peanut, PCR-based detection, S109

$-S$. sclerotiorum: ascospores, environmental factors in North Dakota, S164; on Brassica napus, forecasting model, 1186; on Brassica rapa, resistance screening, S128; on canola, ascospore dispersal, S95; on canola, transcript profiles, S126; on dry bean, regression model, North Dakota, S161; on lentil, Washington,
S120; on lettuce, peas, lentils, California and Washington, 470; on lettuce, sclerotial germination, forecast, 621; on lima bean, processing, S174; sclerotia degraded by Coniothyrium minitans, factors, S23; S. minor comparison, oxygen in soil, S125; on snapbean, hierarchy model, S107; on soybean, oxalic acid, S163; on sunflower, resistance, $\mathrm{S} 11$

Sclerotiniaceae, overview, S134

Sclerotium rolfsii

- on hosta, resistance, S125

- overwinter survival, S125

Scofield, S., S16

Scoles, G. J., 842

Sconyers, L. E., S181, S183

Scorza, R., S82

Scott, E. S., 1284

Scott, J., S48

Scott, S., S116

Sealy, R. L., S31

Seaver, D., S147

Seaweed, soybean and tomato root disease managed by, S112

Sechler, A., 803, S94, S104, S105, S106

Seck, A., S106

Secor, G. A., 835, 1331, S15, S160

Seebold, K. W., S183

Seem, R. C., 512, 979, 1356, S5, S38, S80, S119, S141

Seemüller, E., 964

Seijo, T. E., 1130, S106

Semenov, A. M., S106, S154

Semenov, V. M., S106

Semenova, E. V., S106

Sémétey, O., 72

Seo, J., S106

Septoria spp.

-S. citri, species-specific primers, California, S36

$-S$. passerinii, on barley: genetic structure, Northern Great Plains, 938; resistance genes, mapping, 155; sequence tagged site markers, 162,538

Serdani, M., S110

Serfling, A., 523

Sergienko, V. G., S163

Serratia marcescens, niche adaptation, hosts, S139

Setamou, M., S25

Sether, D. M., S106, S112

Setosphaeria turcica, on maize, races 1, 23, and $23 \mathrm{~N}$, variation in U.S.A., 1501

Seyb, A., S106, S154

Shabana, Y. M., S107

Shah, D. A., S107, S179

Shahsavan Behboodi, B., S98

Shands, H., S151

Shaner, G. E., 1022, 1608, S85

Sharma, N., S107

Shaw, M. W., 297, 1451, S55, S96

Sheedy, J. G., S167, S170

Shelman, T., S124

Shelver, W. L., 1245

Shepherd, L. M., S35

Sherbik, A. A., S60

Sherman, D. J., S105

Sherwood, J. E., S3, S115

Shetty, H., S107

Shew, B. B., S109, S134

Shew, D., S56

Shew, H., S29, S38, S42

Shi, A., S107

Shi, X., S107, S121

Shiel, P., S147

Shier, T. W., S

Shier, W., S1

Shim, H., S86

Shimizu, J., S108

Shin, M., S108

Shintaku, M., S97

Shtienberg, D., 1284
Shu, Q., S120

Si, N. G., 643

Sickley, T., S81

Sillero, J. C., 60

Silva, L. H., S33

Silva-Rojas, H. V., S6, S108

Sim, S., 767

Simard, M., S179

Simeto, S., S91

Simko, I., S149

Simões, I. C., 702

Simon, S., S186

Singh, R. P., S37, S136, S137

Singh, R. S., S55

Singh, S. P., S30

Sipes, B. S., S50, S108

Sipos, T., S5

Siqueri, F. V., S33

Sisson, A. J., S108

Sisterson, M. S., S108

Sivamani, S., S29

Six, D. L., 1177

Skantar, A., S23, S82, S152

Skaria, M., S25, S60

Skatenok, O. O., S59

Skelsey, P., S109

Slininger, P. J., S104

Smant, G., S103

Smart, C., S12, S153

Smilanick, J. L., S78

Smiley, R. W., S167, S170

Smith, A. H., 132

Smith, B. J., S180, S182, S183

Smith, C. A., S109

Smith, C. W., S34

Smith, D., S42, S81, S109, S134

Smith, J. (Miss.), S76

Smith, J. A. (U.K.), 621

Smith, K. P., S149

Smith, L. J., S109, S171

Smith, M., S30, S36

Smith, S., S87

Smith, T. J., S95

Sniezko, R., S168

Snook, M. E., S6

Snover-Clift, K. L., S109

Snowdon, R. J., 1391

Snyder, E. M., S52

Snyder, N. L., S122

Soika, M. D., S77

Soilborne diseases

—bacteria, management, S9

-microbial community management, S153

Soil fumigant (see also Fumigant)

-metam sodium, plastic-mulched soil beds, pathogen survival, S17

Soil microorganisms, microbial inoculants, disease suppressiveness, S180

Soil solarization, organic amendments, laboratory system, 1476

Solano, O., S175

Solanum melongena (see also Eggplant)

—bacterial wilt, diversity in Philippines, 1467

Sonchus yellow net virus, GFP expression, S38

Song, C., S51, S68

Song, J., S110, S146

Sorghum

—disease resistance, stilbene, S67

—inoculation strategies, S37

Sosnowski, M. R., 1284

Soubeyrand, S., 1315

Soule, M. J., S3, S51

Soybean in

-Bean pod mottle virus, genetic reassortment, 79

- Cercospora leaf blight, cercosporin protein, S19

- cyst nematode: on bean, reproduction, S94,

S163; resistance, S72; tillage and rhizosphere relation, $\mathrm{S} 180$

—defense signaling, genomics, S54 
-iron-deficiency chlorosis, mycorrhizae, rotation crops, S112

-Northern stem canker, resistance in South Dakota, S20

-Phytophthora root and stem rot, resistance: components, 655; cytology, S163

- Phytophthora sojae, resistance, 106, 113, S160

- picoxystrobin translocation, S28

-Pythium damping-off, genetic mapping, S101

-root rot: seed treatment, S76; temperature and soil moisture, S76

-rust: in central U.S.A. in 2006, S28; epidemic analysis, U.S.A. and abroad, S54; epidemiology in southeast U.S.A., S22; fungicides for, S181; isolate variation, $\mathrm{S} 4$; leaf wetness, factors in field, S83; light and time effects, S28; pathosystem model, S114; resistant sources in Paraguay, S76; satellite imagery for detection, S85 sentinel plot monitoring, Georgia, S183; spatiotemporal development, factors, S33; spore germination factors, 997; spread in southeastern U.S.A., 1428; urediniospore assay, S9; Virginia, S185

- seed treatments: factors, Arkansas, S5; North Dakota and Illinois comparison, S13

- spore deposition in canopies, S30

-yield, fungicides and insecticides, S88

Soybean dwarf virus, sequence diversity of protein, S114

Soybean mosaic virus

- genetics of seed transmission, S29

- N terminal, symptom determinant, S129

- prevalence in Iowa, S68

— silencing suppressor and symptoms, 366

- strains, phenotypic interaction, S107

-virulence from avirulent strain, S31

Spadaro, D., S44

Spaine, P., S88

Sparks, A., S102, S110, S182

Sparks, D., S127

Spartina spp., Fusarium spp., sudden wetland dieback, S178

Speijers, J., 1011

Spiers, J. M., S64

Spies, C., S110

Spiroplasma citri

-on citrus: infection loci in California, S172; PCR-based detection, S127; yield and quality, California, S74

— genetic diversity, factors, S75

Spore dispersal, deposition rates and stochastic modeling, 1325

Spore trap, electrostatic deposition, electron microscopy, S105

Spotts, R. A., S110

Sprenkel, R., S98

Squash vein yellowing virus, on watermelon, S2

Srivastava, S., S126

Stacey, G., S34, S114

Stack, J. P., 244, S44, S135, S140

Stack, R. W., 592

Stafford, M., S23

Stahl, L. A., S112

Stanger, C., 1451

Staniszewska, H., S178

Stanosz, G. R., S81

Stansly, P. A., S99, S182

Starr, G. C., S61

Starr, J. L., S34

Steddom, K., S110

Stedman, J. K., S110

Steffenson, B. J., S149

Steger, A., S5

Stein, J., 1608, S85, S163, S164

Steiner, U., 1222

Stenger, D. C., 1213, S21, S111

Stenocarpella maydis, on maize, molecular characterization, S35

Stensvand, A., S38
Stephens, R. M., S4

Sternberg, P., S157

Stetina, K. C., S13

Stevens, G., S143

Stevens, M. R., S57

Stevenson, K. L., 187

Stevenson, W. R., 865, S4, S5, S40, S63, S100

Stewart, F., S45

Stewart, J. E., S79

Stewart, L., S119, S155

St. Martin, S. K., 106, 113, S160

Stockmarr, A., 1325

Stockwell, V. O., 244, 1263, S171

Stone, A. L., S26

Stone, C. L., S4

Stone, J. K., S24

Stover, E. W., S58

Strand, J., S92, S140

Strausbaugh, C. A., S111, S171

Strawberry

-anthracnose: flower colonization, S91; native plant isolates, 1130

-Crinivirus, identification, S116

- crown rot, solarization in survival, California, S111

- disease enhancement, fungicides and adjuvants, S75

- powdery mildew, resistance and factors, S38

- spores on leaves, fungicide screening, S180

Strelitzia nicolai, bacterial leaf stripe, symptoms, S106

Streptomyces spp., soil inhabitant, biocontrol, Texas, S39

-S. scabies, on potato, geocaulosphere factors, 1071

Stringfellow, W., S32

Strobel, G. A., S43

Stromberg, E. L., S185

Strong, D., S143

Stuart, R., S142

Stucker, D. S., S149

Sturrock, R. N., 1406

Stutz, J. C., S111, S111

Su, H., S36, S111

Subbarao, K. V., 470, S58, S117, S125

Subere, C. V., S112

Sudal, J. F., S125

Sudarshana, M., S155

Sudini, H., S112

Sudo, K., S112

Sueldo, D., S112

Suffert, F., S44

Sugar beet

— basses richesses transmitted by Pentastiridius sp., proteobacteria cause, 72

-Cercospora leaf spot, epidemiology and modeling, 1550

—root disease, soil assay, S161

-root pathogens, losses, S46

- root rot, bacteria and yeast in Intermountain West, S171

-yellows, Fusarium association, cultivar response, S15

Sugarcane

- aflatoxin, reservoir in Texas, S39

-rust, severity and soil property relation, Louisiana, 748

Sugarcane yellow leaf virus, in Louisiana, S43

Sugawara, T., 1200

Sugiyama, L. S., S84

Sugiyama, T., 1458

Suh, S.-C., 331

Sullivan, R. F., S177

Sultana, V., S31, S112

Summers, C. G., S167

Sun, F., S152

Sun, M., S112

Sun, X., S30, S105

Sun, Y., S112
Sunderwirth, S., S27

Sundin, G. W., S59, S74, S115, S129, S165

Sunflower

—rust: races in Manitoba, S164; resistance-inducing compounds, efficacy, 179

- Sclerotinia head rot, resistance, S5

Suppressive soil

-fungal community, taxonomic macroarray, S50

-nematode, management, S154

- soybean sudden death syndrome, S154

Susaimuthu, J., S113

Sutherland, M. W., S12

Sutton, T. B., 1440, S30, S69, S122

Sutula, C., S61

Suzuki, J., S23

Swanson, J. K., S77

Sweet potato

-Rhizopus soft rot, fungicides, S31

- virus: complex, tospovirus, S181; DNA markers, Kenya, S76; suppression by graft-transmissible agent, S23; time lapse and symptom, S74

Sykes, V. R., S113

Systma, R., S121

Szabo, L. J., 717, S8, S113, S136

Szekeres, A., 532

Szemes, M., S12

Sztejnberg, A., 813

Szurek, B., S8

Tabanca, N., S64

Tabiki, T., S84

Tabor, G. M., S113

Taheri, P., 373

Takahashi, T., 1200

Takahashi, Y., S127

Tally, A., S45, S87

Tambong, J. T., S113

Tan, A., S144

Tang, J., S86

Tangen, K., 1040

Tanguay, P., 1040, S35, S53

Tanio, M., S84

Taphrina deformans, on peach:

- seasonal dynamics, 352

- spore production and budding factors, 359

-weather effects, 1625

Tatalovi, N., S113

Tate, M. E., 907

Tattar, T. A., S114

Tauxe, R. V., S139

Tavantzis, S. M., S8

Taylor, G., S92

Taylor, R. J., S160, S164

Teaching

- course construction, S155

-epidemiological concepts, modules, S110

— lab activities, web-based, scientific method, S31

- podcasts for course, S26

Te Beest, D., S114

Teffeau, M., S136

Teliz-Ortiz, D., S6

Temple, T. N., 1263, S171

Temsah, M., S102

Termorshuizen, A. J., S154

Tewoldemedhin, Y., S114

Thammiraju, S. R., S108

Thannhauser, T. W., S39, S40

Thekke Veetil, T., S114

Theobroma cacao

—black pod: review, symposium, 1640; yield effect, symposium, 1650

-Ceratocystis wilt, symposium, 1648

- frosty pod disease: review, symposium, 1640; symposium, 1644

—industry view of diseases, symposium, 1658

- selection program, marker assisted, symposium, 1664

—vascular-streak dieback, symposium, 1654

—witches' broom, review, symposium, 1640 
-worldwide threats to production, symposium, 1634

Thibivilliers, S., S114

Thoirain, B., 99

Thomas, C., S92, S166, S170

Thomas, J., S44

Thomas, M. R., 930

Thomas, S. L., S126

Thomas, W. K., S157

Thompson, J., S113

Thompson, S. M., S162, S164

Thon, M. R., S25

Tian, M., S114

Tian, S. P., 260

Tiffany, M., S109

Tillage, peanut leaf spot, characterization, 187

Tilletia spp., teliospore mortality, biofumigant, S41

-T. indica, on wheat: resistance, S37; soil solarization effect, S92

-T. tritici, on wheat, Bt-10 gene for resistance, 1397

Timmer, L. W., 1130, S69, S79

Timmerman-Vaughan, G., S62

Timudo, O. E., S45

Tisserat, N., S11, S13, S14, S59, S61

Tkachi, N., 396

Tobacco (see also Nicotiana spp.)

-black shank: azoxystrobin and phosphorous acid, S12; mustard for management, S181

- target spot, azoxystrobin for, S183

Tobacco ringspot virus, detection with PT-PCR method, S62

Tobiasz, M., S178

Toda, T., S109

Tolin, S., S61, S148, S184

Tomaso-Peterson, M., S91, S114, S128

Tomato

- bacterial speck, plant activators and host response, $\mathrm{S} 12$

-bacterial spot: phosphorous acid management, $\mathrm{S} 121$; seed infection, $\mathrm{S} 132$; systemic resistance induced, 429

-bacterial wilt, managenent with phosphorous, S52

- chlorine dioxide treatment, S69

- crinivirus co-infection, S124

-damping-off management, Mexico, S175

-foliar and fruit diseases, growth-promoting rhizobacteria, resistance, $\mathrm{S} 181$

— fruit breakdown, S8

- geminivirus: determination, Central America, S176; recessive allele and viral movement, 930 - grafting, jasmonic acid pathway, S99

-Meloidogyne spp., management programs, S20

-mycovirus-like dsDNA, S103

—picorna-like virus, Mexico, S98

-Rhizoctonia, inhibition by Monarda herbage, $\mathrm{S} 44$

—root knot nematodes and aphids, resistance role of ethylene, S70

- soilborne disease, management by grafting, S99

- stolbur disease, phytoplasma in Turkey, S103

-tomato leaf curl and yellow leaf curl, West Africa, DNA complex, S154

- transformants, resistance derived through Agrobacterium, $\mathrm{S} 23$

- transgenic, resistance enhancement to bacteria, protein, 900

- tymovirus, characterization, S67

Tomato chlorotic mottle virus, molecular and biological characterization, diversity in Brazil, 702

Tomato leaf curl virus, geminivirus control, gene silencing, S22

Tomato ringspot virus, on apple, detection, S80

Tomato spotted wilt virus

-on lettuce, Chile, S101

—on peanut, factors, S87

-on tobacco: Actigard to control, S76; management, S84; progress in North Carolina, S79
- on tomato and petunia, alternative oxidase, S68

- thrips, oils and particle film effects, S98

Tombusvirus sp., detection, polymorphism analysis, S45

Tooley, P. W., 492

Torabi, M., S98

Torbert, H. A., S180

Torrance, R., 1298, S182

Tory, D., S45

Toševski, I., S54

Toussaint, V., S23

Trapero, A., S79

Trapero-Casas, A., 1600

Traquair, J. A., S115

Travers, S. E., S36

Travis, J. W., S44, S83

Treder, K., S77

Tredway, L. P., S29, S56, S77

Tree, health in metropolitan area, Phoenix, S111

Tremblay, D., S42

Trent, M. A., S167

Tribodet, M., S101

Trichoderma spp., on Agaricus and Pleurotus spp., green mold, 532

-T. hamatum, on tomato, gene expression modulation, 429

-T. koningiopsis, on corn, biochemical features, S19

Trierweiler, B., S33

Trigiano, R. N., S64

Tripathi, S., S23

Tripathy, S., S146, S160

Triplett, L., S115, S165

Trottet, M., S27

Trouillas, F. P., S115

Trueman, C. L., S115

Trujillo, K., S3, S115

Tsai, W., S22

Tsai, Y.-C., 900

Tsang, S., S129

Tsuchiya, T., S115

Tsuda, S., 412, 787

Tubajika, K., S116

Tuber aestivum, mycorrhiza establishment, biology, S94

Tuberculina persicina, on onion rust, conidiogenesis, S115

Turechek, W. W., 1164, S116, S170

Turfgrass

-dollar spot: fungicide spray volume, S73; silicon, S42

- fairy rings, identification, $\mathrm{S} 77$

-Magnaporthe grisea, resistance, 170

-management systems, nitrogen-fixing bacteria, S89

—rapid blight, S170

Turgeon, G., S49

Turina, M., S50, S98, S119

Turnbull, G. D., S49

Turner, M. A., S118

Turnip ringspot virus, new virus in Ohio, S57

Turnip yellow mosaic virus, RNA, encapsidation, S116

Tusiime, G., S63

Tuttle, A. F., S177

Tweddell, R. J., S178

Twieg, E., S64, S129

Tyler, B., S75, S146, S160, S184

Tyler, D. D., S180

Tylka, G. L., S113

Typhula spp., on turfgrass, chlorothalonil effect, S11

Tzanetakis, I. E., 37, S60, S71, S116

Uchida, J. Y., S127

Uday Shankar, A. C., 1526

Uddin, W., S56

Uncinula necator, on grape, quality of juice and wine affected by, 1356
Unger, S., 780

Upchurch, R. G., S117

Uppalapati, S. R., S120

Urban plant pathology, model, informatic, S111

Úrbez-Torres, J., S117

Uribe, P., 632, S117

Urocerus taxodii, wood decay, S123

Uromyces spp.

-U. salsolae, on Russian thistle, host range, S19

- U. transversalis, on gladiolus, first report, S105

-U. viciae-fabae, on faba bean, resistance mechanisms, 60

Urwin, P. E., S144

Useman, S., S178

Ustilago spp.

-U. hordei: farnesyltransferase duing mating, S3; growth-inhibiting proteins, S115

- U. maydis: teliospore formation, stimulator, S55; virus H1, evolutionary history, S118; virus $\mathrm{H} 1$ exclusion phenomenon, S118

Uyeda, I., 544

Uyemoto, J., S4, S171

Vágvölgyi, C., 532

Vaillancourt, L. J., 438, S25

Vaira, A., S117

Valent, B., S145

Vallad, G. E., S117

Vallota mosaic virus, Ornithogalum mosaic virus relation, $\mathrm{S} 45$

Valverde, R. A., S103, S117

Van Alfen, N. K., S50

van Brouwershaven, I. R., 1119

Van Bruggen, A. H., S106, S154

Vance, V. B., S144

Vandemark, G. J., 1290, 1519, S166

van de Mortel, M., S117

van den Beld, H. E., 1119

van den Berg, F., 1512

van den Bosch, F., 202, 1512, S114

Van der Meij, J., S131

van der Werf, W., 945, S109

van Doorn, R., S12

van Loon, L. C., 239, S7

VanRij, N., S85

van Sluys, M., S14, S21, S61

van Vossenberg, B. T. L. H., 1119

Van Winkle, D., 1245

Vargas, A. M., S118

Vargas, J. M., Jr., S134

Vega, R., S175

Vegetables

- cropping system, tospoviruses in India, S97

- downy mildew, mandipropamid, S45

Veitía, M., S175

Venard, C., 438

Venette, R. C., S138

Venturia spp.

$-V$. inaequalis: on apple, fungicide resistance, S93; on apple, myclobutanil resistance, Virginia, S70; on apple, resistance in Indiana, S27; appressoria, melanization requirement, 1222

- V. pirina, on pear, strobilurin resistance, California, $\mathrm{S} 93$

Venugopal, S. C., S54

Vera Cruz, C. M., S18

Verbeek, M., S74

Verbena $\times$ hybrida, Carlavirus of, sequence analysis, S60

Verdier, V., S8

Vereijssen, J., 1550

Veronese, P., S118

Verticillium spp., on Arabidopsis, genomics, S118

-V. albo-atrum, on alfalfa, quantifying with PCR assay, 1519

- $V$. dahliae: on chile pepper, flooding effect, S103; on chile pepper, Phytophthora capsici interaction, 37; host preference, Iran, S8; on mint, secondary spread, S168; on potato, colonization 
dynamics, S4; on potato, PCR for detection, 865; races, PCR method, S58; on spinach, resistance screening, S118; on sunflower, resistance sources, $\mathrm{S} 164$

-V. longisporum, on Brassica napus, interspecific hybridization, 1391; symptoms, on Brassica napus, cover photo, November

Vervoort, J., S7

Viator, R. P., S43

Vicia faba

-Citrus exocortis viroid isolate, host effect, 1004

—rust, resistance mechanisms, phenylpropanoid effect, 60

Vidalakis, G., S44

Vidaver, A. K., 803, S161

Vigna unguiculata, ashy stem blight, resistance and mapping, $\mathrm{S} 80$

Vilchez, M., S36, S111

Villarroel-Zeballos, M. I., S118

Vine, B. G., S60

Viruses

— array-based technology, detection, S153

- designer particles, nanotechnology, S145

-detection, microarray hybridization, S43

- geminiviruses: methylation as defense, S154; tomato resistance, recessive allele and viral movement, 930

- gene regulation, biotechnology, S144

- gene silencing, function, S145

- metagenomics for identification, S81

-mycoviruses, Rosellinia necatrix infection, 278

-ornamental crops, prevention, S131

-on ornamentals: new and emerging, S131; Tymovirus, S131

- perennial plants, new and emerging, S131

- Potyvirus detection, imported germplasm, S82

-resistance and transgenic plants, risk assessment, S144

-ribosomal proteins, differential requirement, S126

-RNA: independent translation, S77; microarray detection, DNAs from infected plants, 119

- RNA silencing, plant interaction, S144

-seed transmission, symplastic pathways, S132

- tobamovirus, on ornamentals, management, S131

- totiviruses, on blueberry and tomato, new genus, S116

—vectors, biomedicals, S144

Vodak, M., S178

Voegel, T. M., S118

Voegtline, M., S144

Voelker, S., 1558

von Tiedemann, A., 1186, 1391

Voth, P. D., S118

Vyn, T. J., S106, S154

Waalwijk, C., 971, 1112

Wade, L., S2

Wager-Pagé, S., S135

Wahle, E. A., S46

Waitea circinata, on bluegrass, genetic diversity, distribution, S21

Wakefield, L., S119

Walcott, R. R., S132

Waldrop, T. A., S74

Waldrop, V. C., S34

Walker, M., S127

Walker, N. R., S16, S119

Walker, S. E., S12

Walkinshaw, C. H., S119, S183

Wall, D., S143

Wall, M. M., S84

Wallwork, H., 907

Walnut, Aspergillus flavus and A. parasiticus, cultivar resistance, $\mathrm{S} 169$

Walter, S., S13

Wamishe, Y. A., S119

Wan, C. A., S95

Wang, D., S17
Wang, G.-L., 170, S52

Wang, H. (Miss.), S67

Wang, H. M. (China), 643

Wang, J. (Calif.), S119

Wang, J. (Mo.), S98

Wang, J. (USDA), S64

Wang, J. X. (China), 1584, S68

Wang, K., S119

Wang, L., S120

Wang, M., S108, S171

Wang, N., S120

Wang, X., S67, S98, S120, S146, S184

Wang, Y., S29

Wang, Z., S77, S106

Wangdi, T., S120

Ward, D. L., S125

Ward, E., 297

Ward, R., S136

Ward, T. J., 1434

Washington, J., S50

Wasilwa, L. A., 1305, S121

Watermelon

- anthracnose and gummy stem blight, cover crop, S130

-Fusarium wilt, management and races, S176

-mycorrhizae, transplant inoculation, S122

-vine decline: management in Florida, S99; resistance in Florida, S59; symptoms, cover photo, February; whitefly population management, $\mathrm{S} 182$

Watling, M., 621

Watson, A. K., S179

Watson, C. J. W., S167

Watson, L. J., S28

Wayadande, A. C., S18

Weaver, M. A., S13, S121

Webb, S. E., 145, S2, S70

Wechter, W. P., S34

Wedge, D., S64

Wei, J., S144

Wei, T., 712

Wei, W., S121

Wei, Y., S115

Weibel, E., S177

Weiland, J. J., 1245

Weller, D. M., 250

Welliver, R., S80

Wells, L. W., S44

Welser, M., S38

Welti, R., S36

Wen, A., S121

Weng, Z., S121, S122

Weon, H., S62

Westbrook, A., S30

Westerdahl, B., S143

Westphal, A., S106, S122, S154, S155

Wharton, P. S., S3, S7, S122

Wheat

- azoxystrobin for disease control, seasonal variation, S58

-bunt, Bt-10 gene, 1397

- common root rot and Fusarium crown rot, germplasm evaluation, S164

- crown rot, partial resistance, $\mathrm{S} 12$

- disease management strategies, Minnesota Red River Valley, S80

-durum, leaf rust, world collection sequence diversity, 574

- epidemic in Red River Valley, Minnesota, S161

-Fusarium spp., Microdochium nivale, crop residue effect, 971

-Fusarium crown and foot rot, Idaho, Australian cultivars, S124

-Fusarium head blight: antagonists, S104; and deoxynivalenol, S98; deoxynivalenol response, S13; fungicide, S164; infraction timing, S123; inoculum density and weather factors, 1608; maize residues and head-borne inoculum, S163; models, S163; resistance locus, 592; tebucona- zole effect, deoxynivalenol, 211; triazole-based fungicides, S90

— gene silencing, BSMV-based virus, S16

- Karnal bunt: inoculation method, S37; model in Texas, S124

-leaf rust: latent period heritability, 1022; populations in Asia and Caucasus, 1141; resistance gene identification, PCR analysis, S60; worldwide collection, 344

— pests, diseases, and disorders, diagnosis, S59

-Phaeosphaeria nodorum, seed transmission, 584

-Piriformospora indica, biocontrol agent, 523

- powdery mildew, detection method, S33

- Rhizoctonia and Pythium spp., distribution in Washington, S105

-rust, resistance genes, isogenic lines, 1083

- speckled snow mold, mapping of trait locus, S84

— stem rust, race Ug99, global threat, S136

-stripe rust: adult-plant resistance, gene mapping, S21; dispersal in plots, modeling, 1315; race-specific resistance and basal defense, analysis, S24; resistance by 'Alpowa', gene mapping, S169; strategy for control, S166

- $\tan$ spot, phenotypes and genotypes, races, 694

- trichothecene-responsive gene, S33

-yellow rust, epidemic growth rate, weather patterns, 202, 1512

Wheat streak mosaic virus

- Maize chlorotic mottle virus infections, synergism, double maize, 1213

- post-transcriptional gene silencing, S111

-on wheat, resistance, S168

-yield effect, S61

-yield and soil water, S124

Wheeler, M. H., S65

Wheeler, T. A., S183

Whipps, J. M., 621

Whisson, S., S146

Whitcher, L., S33

White, D. G., 311

White, F., S84

Whitehouse, C. A., S94

Whitham, S., S117, S126, S129, S145

Whitten Buxton, K. R., S122

Whitworth, J., S89, S153

Wichmann, G., S141

Wickert, E., 1543

Wicklow, D. T., S94

Wickramasinghe, W. K., S123

Wicks, T. J., 1284

Wilcox, W. F., 512, 1356, S5, S80, S130, S141

Wildermuth, G. B., S12

Wiley, G. B., S81

Wilhelm, M., S123

Wilkinson, J. R., S1

Wilkinson, M. J., 1644

Williams, J. H., S148

Willocquet, L., S123

Willyerd, K. T., S123

Wilson, A. D., S123

Wilson, C. R., S53

Wilson, J. N., S183

Wilson, R. K., S156

Win, J., S146

Windels, C. E., 484

Windes, J. M., S92, S124

Windham, A. S., S64

Windham, M. T., S64

Wingfield, B. D., 825

Wingfield, M. J., 825, S27, S91

Wintermantel, W. M., S124

Wirsel, S. G. R., 523

Wise, K. A., S124, S165

Wise, R., S84

Wisler, G., S61

Wisniewski, M., 1491, S69, S185 
Wittmeier, D. S., S164

Woffenden, B., S186

Woloshuk, C., S29, S56, S148

Wolters, P. J., S149

Wong, F. P., 857, S21, S26, S56, S128

Wood, sapstain, genes, Agrobacterium-mediated integration, 1040

Wood, S., S152

Wood Import Pest Risk Assessment and Mitigation Evaluation Team, risk assessments, S41

Woods, D. M., S124

Woodward, J. E., S183

Workneh, F., S124

WormBase Consortium, S157

Wright, D., S30, S33, S54, S63, S83

Wu, B. M., S125

Wu, B.-Y., 304

Wu, D., S120

Wu, H.-W., 287

Wu, J., 405, S130

Wu, M., 1590

Wu, X., S142

Wu, Z., S125

Wunsch, M. J., S125

Wyenandt, A., S179

Wyenandt, C. A., S125

Wylie, T., S156

Wyse, D. L., S112

\section{Xanthomonas spp.}

$-X$. axonopodis: on citrus, diagnosis in packing facilities, S105; on citrus, field dispersal, S11 on citrus, spatial pattern, leafminer role, Brazil, 674; pathogenicity determinants, S8; on soybean, seed detection using PCR, S48

-X. campestris: on banana, PCR for detection, S63; on bean, flower and seed color linkage, S30; on cabbage, detection, hot water treatment, S59; on cruciferous weeds, genetic diversity, California, 803; effector as repressor, transcriptional response, S145; on mango, pathovar identification, 1568; sequence typing scheme, multi-locus, S105

-X. euvesicatoria: control by $X$. perforans, S46; on tomato, biocontrol, 429

-X. fragariae, on strawberry, Q-PCR primers for detection, S116

$-X$. oryzae: diagnostic molecular markers, S61; polysaccharide enzyme genes in mutants, S52

-X. perforans: bacteriocins, characterization, $\mathrm{S} 71$; on tomato, management with Actigard, S121

$\mathrm{Xi}, \mathrm{L} ., \mathrm{S} 54$

Xiao, C. L., S57, S65, S171

Xin, J., S88

Xing, L., S106, S122, S154

Xiong, Q., 405

Xiong, Z., S121, S122

$\mathrm{Xu}, \mathrm{J} ., \mathrm{S} 128$

Xu, X. B., 260

Xu, Z., S125, S125

Xue, B., S126

Xue, H., S117
Xylella fastidiosa

—on alfalfa, inoculum source, S108

-on almond: genome sequences, S21; rootstock seedling resistance, California, S22; seasonal susceptibility, S17

-autotransporter, outer membrane, S72

- on blueberry, new disease, S20

-on chitalpa, strain analysis, S96

— chitalpa and grape, phylogenetic analysis, S96

-on citrus and coffee: genetic diversity, 1543 . isolates in Brazil, S3

- complementation analysis, integration vector, S71

- genomic variations, diagnosis, S64

-on grape: fimbrial and afimbrial adhesions, 318; global gene expression, S120; movement and biofilm in xylem, S26; proteomic expression, S127; temperature and variety effect, S76; vectors in North Carolina, 1440; virulence and regulatory pathways, $\mathrm{S} 107$

- hemaglutinans, resistance role, S118

-on ornamentals, phylogeny, California, 857

- peptide effect on cell surface, S14

— polysaccharide attachment, S57

-in sharpshooter foreguts, S6

— strain diversity, North and South America, 1338

— strains from California, Georgia, and Florida, S67

- virulence and biofilms, mutants, S46

-in woody plant tissue, detection method, S37

Yaghmour, M. A., S126

Yakabe, L. E., S126

Yamaguchi, T., 1458

Yamamoto, H., 557

Yamamoto, P., S70

Yamatsuta, T., 1200

Yan, G. P., 668, S171

Yang, B., S84, S126, S127

Yang, C., S126

Yang, L., S127

Yang, Q., S120

Yang, S., S52

Yang, X., S28

Yang, Y., S104

Yangrae, C., S78

Yano, K., 1458

Yao, H. J., 260

Yao, J., S64, S75, S127

Yap, M., S127

Yates, I. E., S127

Yedidia, I., 1150

Yeh, A., S51

Yeh, S.-D., 287

Yin, C., S150

Yin, Y., S156

Yip, K. N., S4

Yoder, K. S., S70, S185

Yokomi, R. K., S74, S75, S104, S127, S172

Yonce, H. D., S42

Yonts, C. D., S45

Yoshida, K., 278

Yoshida, M., 1054

Yoshikawa, N., 1200
Young, B. A., 1213, S111

Young, C. (Ohio), S128, S146

Young, C. A. (Okla.), S121

Young, C. S. (U.K.), 621

Young, G., S72, S71

Young, J., S114, S128

Yu, H., S67

Yu, J. M., 366

Yu, K., S67

Yuan, S. K., 643, 1584

Yuen, J. (Sweden), 1484

Yuen, J. M. (Fla.), S85

Zabala, F., S128

Zablotowicz, R. M., S1, S75

Zaffarano, P. L., S128

Zaid, M., S58

Zamanizadeh, H., S98

Zambino, P. J., S128, S138

Zapala, F., S95

Zasada, I. A., S156

Zearfoss, A. D., S128

Zee, F., S112

Zehr, U., S97

Zelaya-Molina, L. X., S6, S108

Zelenev, V. V., S106, S154

Zeller, K. A., S129

Zenbayashi-Sawata, K., 598

Zhai, C., S120

Zhang, C. (Iowa), S129

Zhang, C. (Ky.), 79, 1255

Zhang, H., S25, S168

Zhang, J., S22, S172

Zhang, L., 1590

Zhang, N., S153

Zhang, S., S64

Zhao, B., S106

Zhao, J., S21

Zhao, X., 1348, S29, S64, S72

Zhao, Y., S45, S53, S59, S121, S129, S165

Zhong, S., S113, S126, S127

Zhou, L., S160

Zhou, M. G., 1584

Zhou, X.(China), 405, S130

Zhou, X. G. (Md.), 461, S130, S174, S176

Zhou, Y., S154

Zhou, Z.-H., 304

Zhu, S. S., 643

Zhu, X., S145

Zidack, N., S43, S50, S83

Zitomer, N. C., S41, S52

Zitter, S. M., S130

Zitter, T. A., S43

Zody, M. C., S146

Zolobowska, L., 1298

Zucchini yellow mosaic virus, cross protection:

- cover photo, March

-mutant, 287

Zullini, A., S133

Zumpetta, C., 756

Zygophiala jamaicensis, on apple, conidial movement, S177 